\title{
Ferroptosis Is Involved in Diabetes Myocardial Ischemia/Reperfusion Injury Through Endoplasmic Reticulum Stress
}

\author{
Wenyuan Li, ${ }^{\star}$ Wei Li, ${ }^{*}$ Yan Leng, Yonghong Xiong, and Zhongyuan Xia
}

Myocardial ischemic disease affects the prognosis in perioperative patients. Diabetes can aggravate myocardial injury. The purpose of this research is to investigate the effect of ferroptosis in the process of diabetes mellitus (DM) myocardial ischemia/reperfusion (I/R) injury (IRI). Endoplasmic reticulum stress (ERS) is investigated whether aggravates cardiomyocytes injury. Rat DM+I/R (DIR), cell high glucose (HG), hypoxia reoxygenation (H/R), and high-glucose H/R (HH/R) models were established. Ferroptosis inhibitor Ferrostatin-1, ferroptosis agonist Erastin, ERS inhibitor Salubrinal, and ERS agonist Tunicamycin were administered. Serum creatine kinase-MB (CK-MB), cell viability, lactate dehydrogenase (LDH), malondialdehyde (MDA), superoxide dismutase (SOD), reactive oxygen species (ROS), and cellular ferrous ion concentration were examined. The level of ACSL4, GPX4, ATF4, CHOP, BCL-2, and BAX was detected. Myocardial tissue pathological change was detected by hematoxylin-eosin staining. Cardiac function was monitored by invasive hemodynamic measurements. Evans Blue-triphenyltetrazolium chloride double staining was used to detect the myocardial infarct size. In $\mathrm{DM}+$ sham (DS) (or HG) and $\mathrm{I} / \mathrm{R}$ (or $\mathrm{H} / \mathrm{R}$ ) models, cardiomyocytes were injured accompanied by increased level of ferroptosis and ERS. Moreover, the cell injury was more serious in rat DIR or cell HH/R models. Inhibition of ferroptosis in DIR model could reduce ERS and myocardial injury. Inhibition of ferroptosis in $\mathrm{H} 9 \mathrm{c} 2$ cells $\mathrm{HG}, \mathrm{H} / \mathrm{R}$, and $\mathrm{HH} / \mathrm{R}$ models could reduce cell injury. Erastin could aggravate ERS and cell injury by stimulating ferroptosis in HH/R cell model. Meanwhile, inhibition of ERS could alleviate ferroptosis and cell injury. Ferroptosis is involved in DIR injury that is related to ERS. Moreover, inhibition of ferroptosis can alleviate DIR injury, which may provide a therapeutic regent for myocardial ischemic disease.

Keywords: ferroptosis, diabetes myocardial, ischemia/reperfusion, endoplasmic reticulum stress

\section{Introduction}

D IABETES IS A METABOLIC DISORDER caused by hyperglycemia and insufficient release of endogenous insulin or underutilization (Benninger et al., 2011). Diabetes is a high-risk factor for perioperative complications and cardiovascular disease (Altunkaynak and Ozcelikay, 2016). In myocardial ischemia/reperfusion (I/R) injury (IRI), the ischemic heart gets injured irreversibly, although the heart restores blood flow reperfusion (Korkmaz-Icoz et al., 2015). The pathological changes caused by metabolic abnormalities, such as coronary artery occlusion, decreased vascular compliance, and microvascular disease, usually occur in diabetic patients (Kurmus et al., 2018). As a result, it leads to systolic diastolic dysfunction, ventricular hypertrophy, or myocardial fibrosis (Kurmus et al., 2018).

The tolerance of damaged myocardium to ischemia-anoxia injury is much lower than normal myocardium (Kurmus et al., 2018). Studies have shown that the incidence of myocardial ischemia in diabetic patients is 2.45 to 2.99 times higher than that in nondiabetics (Ndumele et al., 2016). The sensitivity of myocardial IRI in diabetic patients is higher than normal myocardium. This may increase oxidative stress caused by hyperglycemia and excessive reactive oxygen species (ROS) production (Khardori and Nguyen, 2012).

In 2012, Dixon et al. first proposed the concept that ferroptosis is a form of regulated cell death that is dependent on iron and ROS. Ferroptosis is resulted from the accumulation of cellular ROS that exceed the redox contents maintained by glutathione and the phospholipid hydroperoxidases (Dixon et al., 2012). During the process of ferroptosis, the activity of cystine-glutamate antiporter (system Xc-) is inhibited, namely the amount of cystine entering into cells decreases, the amount of glutamate transporting out of cells decreases. The lipid peroxide will accumulate (Dixon et al., 2012; Sui et al., 2018). Then, glutathione peroxidase 4 (GPX4) is inactivated, causing cell death (Dixon et al., 2012).

Department of Anesthesiology, Renmin Hospital of Wuhan University, Wuhan, P.R. China.

*These authors contributed equally to this work. 
Ferroptosis is characterized by the production of ROS and lipid peroxidation during fenton reaction. Ferroptosis is associated with a variety of pathological cell death in some degenerative pathological diseases (Stockwell et al., 2017). Recent studies have shown that endoplasmic reticulum stress (ERS) plays an important role in the process of ferroptosis through the induction of unfolded protein. ERS is characterized by the activation of activating transcription factor 4 (ATF4)-C/EBP homologous protein (CHOP) pathway. Moreover, $\mathrm{CHOP}$ can further induce the cell injury during ERS (Zheng et al., 2017; Lee et al., 2018).

The relationship between ferroptosis and ERS includes the following three aspects. First, the occurrence of ferroptosis is accompanied by the production of ERS (Wang et al., 2019a), which is verified in intestinal epithelial cells (Qi et al., 2019) and some cancer cells, such as pancreatic ductal adenocarcinoma (Zhu et al., 2017), cervical carcinoma (Sun et al., 2015), and fibrosarcoma (Dixon et al., 2014). Through in-depth mechanism research, it is found that the unfolded protein response (UPR) is caused by ferroptosis inducers. The PERK-eIF2alpha-ATF4-CHOP pathway was subsequently activated, which triggers ERS (Lee et al., 2018). Meanwhile, the ferroptosis could promote the cystine-glutamate antiporter system Xc-, which leads to ERS (Rahmani et al., 2007; Sun et al., 2015).

Second, ERS is a cellular response to endoplasmic reticulum dysfunction and can be triggered by ROS (Cao and Kaufman, 2014). More importantly, ROS is produced by the interaction between iron ions and NADPH oxidase in mitochondria during the process of ferroptosis (Shimada et al., 2016). Third, ferroptosis agonists (sorafenib, erastin, sulfasalazine) could activate the ATF4-CHOP pathway (Lee et al., 2018). CHOP-mediated ERS has been proved to play an important role in the $\mathrm{I} / \mathrm{R}$ injury of rat myocardium (Zhang et al., 2013).

The above studies suggest that ERS plays an important role in cell injury in the process of ferroptosis. However, whether ferroptosis is involved in diabetes myocardial IRI through ERS and inhibition of ferroptosis could alleviate myocardial IRI deserve further studies.

\section{Materials and Methods}

\section{Materials}

$\mathrm{H} 9 \mathrm{c} 2$ rat cardiomyocyte cell line was purchased from Wuhan Punosi Life Science and Technology Co., Ltd (Wuhan, Hubei, China). Dulbecco's modified Eagle's medium (DMEM) low sugar medium was purchased from HyClone (Logan, UT). Fetal bovine serum was purchased from Gibco (Grand Island, NY). The cell counting kit-8 (CCK-8) was purchased from Dojindo (Kumamoto, Kyushu, Japan). The Annexin V-FITC/ propidium iodide flow cytometry apoptosis kit was purchased from BD Biosciences (San Jose, CA). Lactate dehydrogenase (LDH), superoxide dismutase (SOD), ROS, and malondialdehyde (MDA) test kits were purchased from Nanjing Jiancheng Bioengineering Institute (Nanjing, Jiangsu, China).

Iron assay kit, ACSL4, and GPX4 primary antibodies were purchased from Abcam (Cambridge, MA). CHOP, ATF4, BCL-2, BAX, and $\beta$-actin primary antibodies were purchased from CST (Boston, MA). Second antibodies were purchased from LI-COR Biosciences (IRDye 800CW; LI-COR Corporate, Lincoln, NE). Cy3-labeled goat antirabbit second antibody was purchased from Proteintech (Wuhan, Hubei, China). The Trizol, Prime-Script RT reagent kit and SYBR Premix Ex Taq kit were purchased from TAKARA (Dalian, Liaoning, China). Erastin (Era), Ferrostatin-1 (Fer-1) and Salubrinal (Sa) were purchased from Selleck (Houston, TX). Tunicamycin (Tu) was purchased from MedChemExpress (Manmouth Junction, NJ).

\section{Animal model establishment and drug administration}

Fifty specific pathogen free male Sprague-Dawley rats (weighing 210-240g) were purchased from Beijing Huakang Biotechnology Co., Ltd (Beijing, China). The animal experiment was conducted in the animal experiment center at a temperature of $25^{\circ} \mathrm{C} \pm 2{ }^{\circ} \mathrm{C}$, relative humidity of $50 \% \pm 15 \%$, and normal circadian rhythm $(12 \mathrm{~h}$ dark $/ 12 \mathrm{~h}$ light) in Renmin Hospital of Wuhan University. All the rats got free water and food. The study protocols were in accordance with the internationally accepted principles and Guidelines for the Care and Use of Laboratory Animals of Wuhan University [Approval No. SYXK (HUBEI) 20140080]. All the rats were randomly equally divided into five groups: normal+sham group (NS), I/R group (I/R), diabetes mellitus (DM)+sham (DS) group, DM+I/R group (DIR), and $\mathrm{DM}+\mathrm{I} / \mathrm{R}+\mathrm{Fer}-1$ group (DIR+Fer-1). Every group included 10 rats. The DS and DIR rat models were built as follows.

The DS, DIR, and DIR+Fer-1 group rats were injected with $1 \%$ streptozotocin $60 \mathrm{mg} / \mathrm{kg}$ once in the tail vein. After 3 days, if the fasting blood glucose level was higher than $16.7 \mathrm{mmol} / \mathrm{L}$, the DS model was successfully built. The other group rats were injected with normal saline in the tail vein. Thereafter, the general conditions for normal and DM rats are recorded in Table 1. On the last day after 8 weeks, the NS group, DS group, I/R group, DIR group, and DIR+Fer-1 group rats were intraperitoneally injected with $1.5 \%$ sodium pentobarbital at a dose of $0.005 \mathrm{~mL} / \mathrm{g}$. They were given electrocardiogram (ECG) monitoring management. After the rats were subjected to endotracheal intubation, the tracheotomy catheter was connected to a microanimal ventilator for 80-90 times/min mechanical ventilation.

The heart rate (HR) and blood pressure were recorded. The rats' hearts were exposed by sternotomy along the left edge of sternum. The left anterior descending (LAD) coronary artery between the left atrial appendage and the pulmonary artery cone was sutured and then covered with saline gauze. If the left ventricle apex for myocardial blanched and ST segment of ECG was elevated, the LAD coronary artery was successfully ligatured. To restore the reperfusion of coronary arteries, the ligature was cut after $30 \mathrm{~min}$ of ischemia. At the same time, the anterior wall of left ventricle turning red and the elevated ST segment of electrocardiogram indicated the successful reperfusion. Then, the coronary arteries restored the reperfusion for $2 \mathrm{~h}$.

Rats in the NS group were only threaded without ligation. Referred to the reported dosage (Zhang et al., 2018), DIR+Fer-1 group rats were intraperitoneally injected with Fer-1 at a dose of $2 \mathrm{mg} / \mathrm{kg}$ until $2 \mathrm{~h}$ before building I/R model. The part of the cardiac apex and serum was collected for the follow-up experiments.

\section{Determination of cardiac function}

Invasive hemodynamic measurements were used to monitor the cardiac function. In brief, the heparin-saline-filled 
Table 1. General Condition of Normal and Diabetes Mellitus Rats

\begin{tabular}{lcclcc}
\hline Group & $\begin{array}{c}\text { Body weight } \\
(\mathrm{g})\end{array}$ & $\begin{array}{c}\text { Food intake } \\
g /(\mathrm{kg} \cdot \text { day })\end{array}$ & $\begin{array}{l}\text { Water intake } \\
\mathrm{mL} /(\mathrm{kg} \cdot \text { day })\end{array}$ & $\begin{array}{c}\text { Heart weight } \\
\text { index }(\%)\end{array}$ & $\begin{array}{c}\text { Blood glucose } \\
(\text { mmol/L) }\end{array}$ \\
\hline Normal $(n=10)$ & $479.6 \pm 30.5$ & $70.2 \pm 6.9$ & $114.5 \pm 9.6$ & $3.6 \pm 0.3$ & $6.5 \pm 0.7$ \\
DM $(n=40)$ & $283.7 \pm 27.0^{\mathrm{a}}$ & $121.4 \pm 10.7^{\mathrm{a}}$ & $280.9 \pm 22.4^{\mathrm{a}}$ & $4.8 \pm 0.5^{\mathrm{a}}$ & $27.8 \pm 2.9^{\mathrm{a}}$ \\
\hline
\end{tabular}

Results are expressed as mean \pm standard deviation.

${ }^{\mathrm{a}} P<0.01$, compared with normal rats.

DM, diabetes mellitus.

catheter was inserted into the right common carotid artery, and separately passed through the aortic arch, the left atrium, the mitral valve, and the left ventricle for measurement. The other end of the catheter was connected to a pressure transducer (Yixinda, Shenzhen, China). Measurements were taken at $10 \mathrm{~min}$ before ischemia and $2 \mathrm{~h}$ after reperfusion. HR, left ventricular systolic pressure (LVSP), maximal rate of increase of left ventricular developed pressure $(+\mathrm{dp} / \mathrm{dt})$, and maximal rate of decrease of left ventricular developed pressure $(-\mathrm{dp} / \mathrm{dt})$ were monitored by electrophysiolograph purchased from BioPAC (Goleta, CA). Data analysis was performed by AcqKnowledge 4.0 software.

\section{Triphenyltetrazolium chloride determination of myocardial infarction area}

Myocardial infarction area was detected by Evans Blue and triphenyltetrazolium chloride (TTC) double staining. Six rats in each group were randomly selected, and the LAD coronary artery was ligated. The rats were rapidly injected $1 \mathrm{~mL} 5 \%$ Evans Blue from the femoral vein. After the myocardial blue staining and nonblue staining area was clearly distinguished through observation, the aortic arch was clipped by hemostasis. The heart was then quickly extracted, rinsed with $4^{\circ} \mathrm{C}$ PBS solution, and placed vertically. The heart was frozen at $-20^{\circ} \mathrm{C}$ for $30 \mathrm{~min}$. The frozen heart was placed in a special heart slice trough. Five pieces of heart slices $\sim 1 \mathrm{~mm}$ thick were prepared, placed in the $1 \%$ TTC solution in a $37^{\circ} \mathrm{C}$ incubator for $15 \mathrm{~min}$ in the dark. The slices were then fixed in $4 \%$ paraformaldehyde for $30 \mathrm{~min}$.

Each area of the myocardium was calculated by ImagePro Plus 6.0 software. The nonischemic myocardium stained with Evans Blue was dark blue. For the ischemic myocardium stained with TTC staining, brick red myocardium was defined as the area at risk (AAR), and pale myocardium was defined as the infarct area (IA). The percentage of myocardial infarction area was calculated as the percentage of infarcted myocardium area to the ischemic myocardium area (IA/AAR\%).

\section{Cell model establishment and drug administration}

H9c2 cells were cultured in a cell culture chamber containing $10 \% \mathrm{CO}_{2}$ at $37^{\circ} \mathrm{C}$. When $\mathrm{H} 9 \mathrm{c} 2$ cells grew to $70-80 \%$ density, the trypsin with ethylenediaminetetraacetic acid (EDTA) was used to digest the cells. The cells were planted in six-well plates. The cells were divided into normal group, high-glucose (HG) group, hypoxia reoxygenation group (H/R), high-glucose hypoxia reoxygenation group (HH/R), $\mathrm{HH} / \mathrm{R}+$ Erastin group $(\mathrm{HH} / \mathrm{R}+\mathrm{Era}), \mathrm{HH} / \mathrm{R}+$ Erastin+Salubrinal group $(\mathrm{HH} / \mathrm{R}+\mathrm{Era}+\mathrm{Sa}), \mathrm{HH} / \mathrm{R}+\mathrm{Salubrinal}$ group $(\mathrm{HH} / \mathrm{R}+\mathrm{Sa})$, $\mathrm{HH} / \mathrm{R}+$ Ferrostatin-1 group (HH/R+Fer-1), HH/R+Ferrostatin-
1+Tunicamycin group (HH/R+Fer-1+Tu), and HH/R+Tunicamycin group $(\mathrm{HH} / \mathrm{R}+\mathrm{Tu})$. After being synchronized with serum-free low-glucose DMEM for $24 \mathrm{~h}, \mathrm{HG}$ medium (glycol concentration of $30 \mathrm{mmol} / \mathrm{L}$ ) was added.

Then, the cells were cultured at $37^{\circ} \mathrm{C}$ for $24 \mathrm{~h}$ to establish HG model. The H/R model was established by hypoxia (volume fraction $94 \% \mathrm{~N}_{2+}$ volume fraction $5 \% \mathrm{CO}_{2+}$ volume fraction $\left.1 \% \mathrm{O}_{2}\right) 4 \mathrm{~h}$ and reoxygenation (volume fraction $90 \%$ atmosphere+volume fraction $\left.10 \% \mathrm{CO}_{2}\right) 2 \mathrm{~h}$. For the $\mathrm{HH} / \mathrm{R}$ cell model, before the last $6 \mathrm{~h}$ for building $\mathrm{HG}$ cell model, the $\mathrm{H} / \mathrm{R}$ cell model was beginning to establish. The above drugs respectively affected at a concentration of $10 \mu \mathrm{mol} / \mathrm{L}$ (Erastin) (Baba et al., 2018; Bai et al., 2018; Liu et al., 2018), $10 \mu \mathrm{mol} / \mathrm{L}$ (Ferrostatin-1) (Baba et al., 2018), $10 \mu \mathrm{mol} / \mathrm{L}$ (Tunicamycin) (Lee et al., 2013; Wu et al., 2014), $20 \mu \mathrm{mol} / \mathrm{L}$ (Salubrina) (Liu et al., 2012, 2016a; Wu et al., 2014). Era and Fer- 1 continuously acted for $24 \mathrm{~h}$ before building cell models. $\mathrm{Tu}$ and $\mathrm{Sa}$ were added $6 \mathrm{~h}$ before building cell models.

\section{Cell viability detection}

Cell suspension was prepared and inoculated into the 96well plate at a density of $5 \times 10^{3}$ cells $/ 100 \mu \mathrm{L}$ per well. After the cells were being attached, they were modeled and administered with the corresponding drugs. The control group was set with only adding DMEM. Each group had six duplicate holes. CCK- 8 was added to the basal medium at a ratio of 1:10 to prepare CCK-8 working solution. Then, the culture solution was removed. CCK-8 working solution for $100 \mu \mathrm{L}$ was added to each well. The cells were incubated for $1 \mathrm{~h}$ in the dark. At last, the optical density value for each well at $490 \mathrm{~nm}$ absorbance was measured by a microplate reader.

\section{Creatine kinase-MB, ROS, SOD, MDA, LDH, and intracellular ferrous ion $\left(\mathrm{Fe}^{2+}\right)$ determination}

The cells and cell supernatant were collected to measure the levels of creatine kinase-MB (CK-MB), SOD, MDA, LDH, and intracellular $\mathrm{Fe}^{2+}$ by assay kits according to the instructions. Then, the intensity was observed by a microplate reader. Following the instructions of ROS assay kit, the cells were incubated with 2',7'-dichlorodihydrofluorescein diacetate (DCFH-DA) probes for $30 \mathrm{~min}$ in the dark. Then, the fluoresce intensity was observed under a fluorescence microplate. The stimulated light wavelength was $485 \mathrm{~nm}$, and the emission light wavelength was $525 \mathrm{~nm}$. ROS level $(\%)=$ fluorescence value of intervention group/control group $\times 100 \%$ (Yang et al., 2009).

\section{Quantitative real-time PCR to detect mRNA expression}

The primers were designed and synthesized by Wuhan Qingke Biotechnology Co., Ltd (Wuhan, Hubei, China). The 
Table 2. The Primers of Quantitative Real-time PCR

\begin{tabular}{lll}
\hline Gene & \multicolumn{1}{c}{ Forward $\left(5^{\prime}-3^{\prime}\right)$} & \multicolumn{1}{c}{ Reverse $\left(5^{\prime}-3^{\prime}\right)$} \\
\hline ACLS4 & TCCAAGCCAGAAAACTCAAGC & GGTGTACATGACAATGGCCAT \\
ATF4 & GTTGGTCAGTGCCTCAGACA & CATTCGAAACAGAGCATCGA \\
CHOP & CTGGAAGCCTGGTATGAGGAT & CAGGGTCAAGAGTAGTGAAGGT \\
$\beta$-Actin & TGCTATGTTGCCCTAGACTTCG & GTTGGCATAGAGGTCTTTACGG \\
\hline
\end{tabular}

primer sequences for ACSL4, ATF4, CHOP, and $\beta$-actin are listed in Table 2. Total RNA for H9c2 cells and myocardial tissue was extracted by Trizol. The RNA was then reverse transcribed into cDNA according to the Prime-Script RT reagent kit instruction. According to the instruction for the SYBR Premix Ex Taq kit, the polymerase chain reaction initiated at $95^{\circ} \mathrm{C}$ for $30 \mathrm{~s}$, followed by 40 cycles of amplification of denaturation at $95^{\circ} \mathrm{C}$ for $5 \mathrm{~s}$, annealing at $60^{\circ} \mathrm{C}$ for $34 \mathrm{~s}$ by using a StepOne Plus device (Applied Biosystems). The $2^{-\Delta \Delta \mathrm{CT}}$ method was used to analyze the data.

\section{Western blotting to detect protein expression}

The H9c2 cells and myocardial tissue were homogenized with precooled RIPA lysis buffer. After being centrifuged $(12,000 \mathrm{rpm} / \mathrm{min})$ for $15 \mathrm{~min}$ at $4^{\circ} \mathrm{C}$, the supernatant was taken to add loading buffer. Then, the extracts were boiled at $100^{\circ} \mathrm{C}$ for $5 \mathrm{~min}$. Sodium dodecyl sulfate polyacrylamide gel electrophoresis (SDS-PAGE) was used to separate the protein extracts. Protein was then transferred to a polyvinylidene fluoride (PVDF) membrane. The membranes were incubated with $5 \%$ skim milk for $1 \mathrm{~h}$. The primary antibodies (ACSL4, 1:1000; GPX4, 1:1000; ATF4, 1:1000; CHOP, 1:1000; BCL-2, 1:1000; BAX, 1:1000; $\beta$-actin, $1: 1000)$ were added to incubate with the membranes at $4^{\circ} \mathrm{C}$ overnight. Fluorescent secondary antibody was incubated for $1 \mathrm{~h}$ at room temperature. The bots were at last analyzed with Odessay software (Li-Cor, Lincoln, NE).

\section{Flow cytometry to detect apoptosis rate of each group}

Each group of treated $\mathrm{H} 9 \mathrm{c} 2$ cells was digested with trypsin. Then, the cells were centrifuged at $1000 \mathrm{rpm} / \mathrm{min}$ for $10 \mathrm{~min}$, and the supernatant was discarded. The cells were washed twice with PBS and centrifuged to remove supernatant. Four hundred microliters buffer solution was added to make cell suspension. The cell suspension was then added with $5 \mu \mathrm{L}$ Annexin $\mathrm{V}$ and $5 \mu \mathrm{L}$ propidium iodide. After being incubated at room temperature for $20 \mathrm{~min}$ in the dark, the cells were detected by the flow cytometry (BD, San Jose, CA) for the apoptosis rate.

\section{Hematoxylin-eosin staining and immunohistochemistry to detect myocardial tissue}

The fresh myocardial tissues were fixed with $4 \%$ paraformaldehyde. After being embedded with paraffin, the paraffin blocks were cut into $3 \mathrm{~mm}$ slices. Then, they were detected with hematoxylin-eosin (HE) staining to assess the morphological changes and damage degree. The protein expression level of ACSL4 in the myocardial tissue slices was detected by immunohistochemistry.

\section{Immunofluorescence staining to detect} protein expression

The cells were fixed with $4 \%$ paraformaldehyde. After being blocked with normal goat serum, the rabbit antirat ACSL4 (1:200) and BAX (1:100) antibodies were incubated with the cells overnight at $4{ }^{\circ} \mathrm{C}$. Cy3-labeled goat antirabbit second antibody (1:50) was incubated for $1 \mathrm{~h}$ at $37^{\circ} \mathrm{C}$ in the dark. $4^{\prime}, 6$-Diamidino-2-phenylindole (DAPI) was added to incubate for $5 \mathrm{~min}$. The magnification light microscope (Olympus, Tokyo, Japan) was used to take images at $200 \times$ fields. The fluorescence intensity was analyzed with ImageJ software.

\section{Statistical analysis}

Statistical analysis was performed using SPSS 17.0 software. The measurement data were expressed as mean \pm standard deviation. The comparison between two groups was analyzed with Student's $t$-test. The comparison among three or more groups was performed by one-way ANOVA (with post hoc analysis by Bonferroni correction). $p<0.05$ indicated the statistical difference.

\section{Results}

Inhibition of ferroptosis during myocardial $1 / R$

in diabetic rats can reduce ERS

and myocardial damage

The in vivo experiments first proved the effect of ferroptosis during myocardial I/R in diabetic rats. The pathological changes of diabetic rats' myocardial tissue with IRI were observed by HE staining. As shown in Figure $1 \mathrm{~A}$, the myocardial tissue structure in NS group was dense and tidy, the myocardial fibers were intact, and no myocardial fibers were broken. The myocardial tissue in DS and I/R groups showed mild disorder of cell arrangement and a few myocardial fibers were broken. In the DIR group, the myocardial tissue showed severe cell alignment disorder, the cells were swollen, and most of the myocardial fibers were broken. The degree of myocardial tissue lesions in DIR+Fer-1 group was significantly reduced compared with the DIR group.

As shown in Figure $1 \mathrm{~B}$ and $\mathrm{C}$, the expression of ACSL4 in rat myocardial tissue was detected by immunohistochemistry. Compared with NS group, the level of ACSL4 was increased in DS, I/R, and DIR group $(p<0.05)$. Compared with DS and I/R group, the ACSL4 protein level was increased in DIR group $(p<0.05)$. After being administered with Fer-1, the level of ACSL4 in the DIR+Fer-1 group was lower than that in the DIR group $(p<0.05)$.

As shown in Figure 1D for TTC staining, compared with NS group, the level of myocardial infarction area was increased in DS, I/R, and DIR group $(p<0.05)$. Compared with DS and I/R group, the myocardial infarction area was 
A
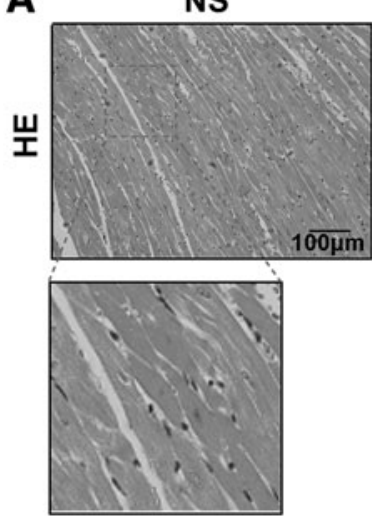

B

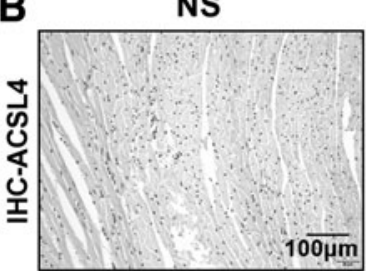

C

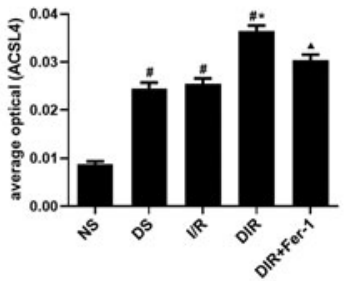

DS
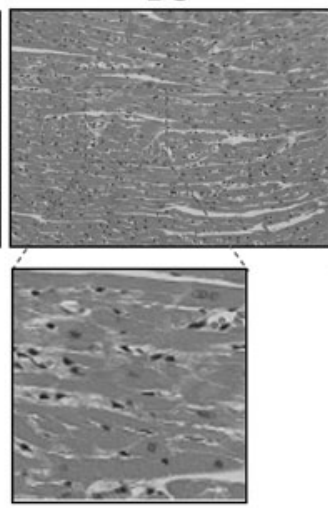

DS

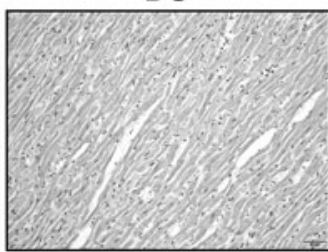

I/R
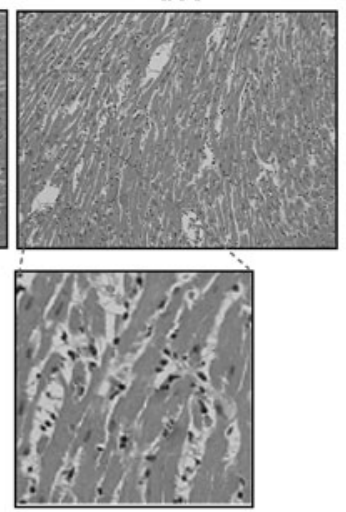

I/R

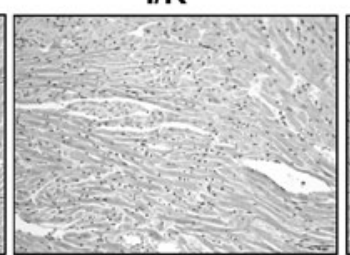

DIR
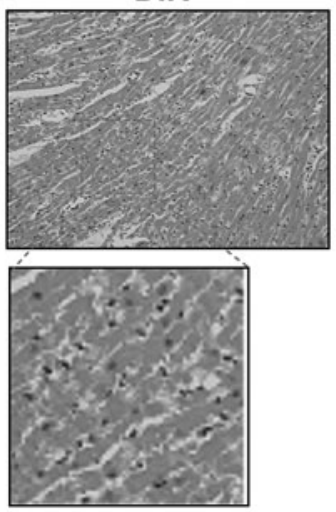

DIR

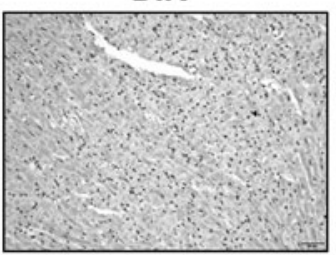

DIR+Fer-1
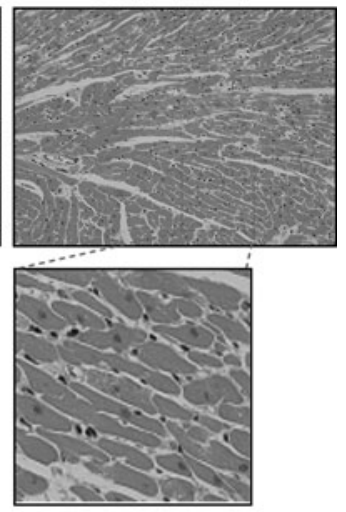

DIR+Fer-1

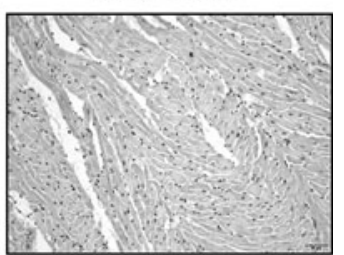

E

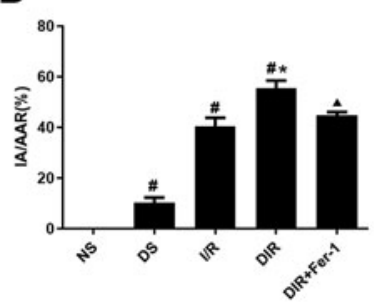

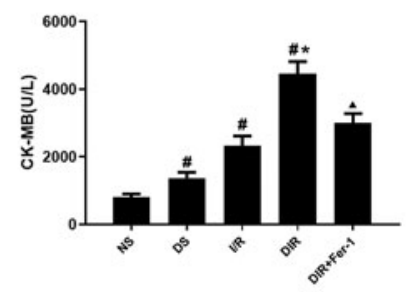

F $\begin{gathered}\text { ACSL } 4 / \beta \text {-actin } \\ \text { aTF } 4 / \beta \text {-actin }\end{gathered}$

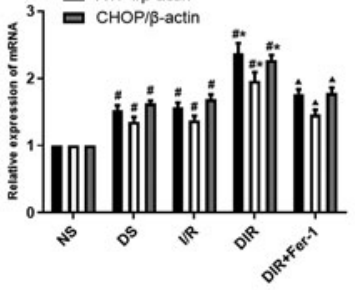

G

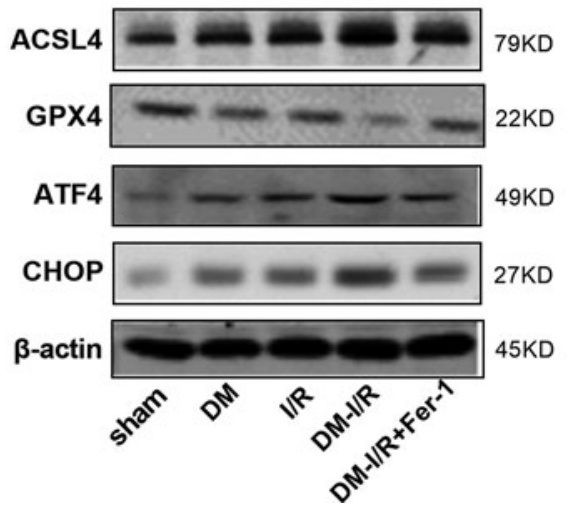

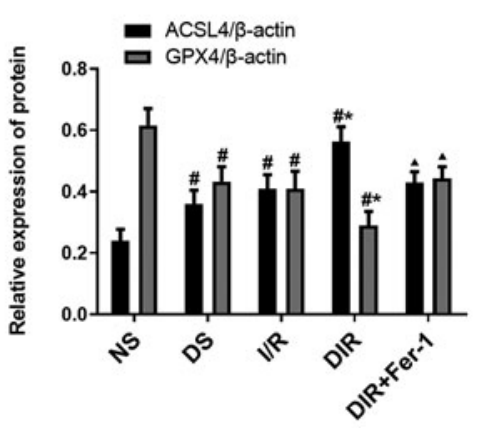

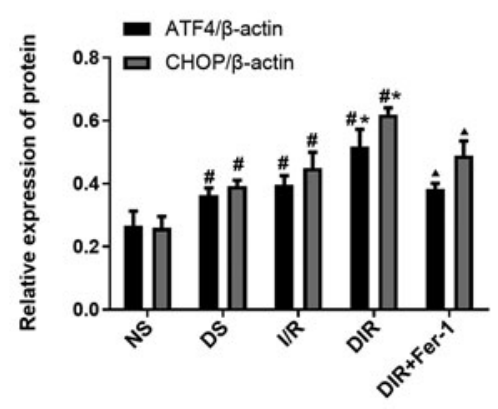

FIG. 1. Inhibition of ferroptosis during myocardial ischemia-reperfusion in diabetic rats can reduce ERS and myocardial injury. (A) Histopathological changes of myocardium were detected by HE staining. (B) The expression of ACSL4 in myocardial tissue was detected by IHC. (C) The expression of ACSL4 in myocardial tissue detected by IHC was analyzed by histogram. (D) The myocardial infarction area was detected by TTC. (E) The CK-MB in serum was detected. (F) The mRNA level of ACSL4, ATF4, and CHOP in myocardial tissue was detected by qRT-PCR. (G) The protein expression of ACSL4, GPX4, ATF4, and CHOP in heart tissues was detected by western blot. ${ }^{\#} p<0.05$, compared with sham group. ${ }^{*} p<0.05$, compared with DM group and I/R group. ${ }^{\boldsymbol{}} p<0.05$, compared with DM-I/R group. CK-MB, creatine kinase-MB; DM, diabetes mellitus group; ERS, endoplasmic reticulum stress; Fer-1, Ferrostatin-1; HE, hematoxylin-eosin; IHC, immunohistochemistry; I/R, ischemia-reperfusion group; qRT-PCR, quantitative real-time PCR; TTC, triphenyltetrazolium chloride.

increased in DIR group $(p<0.05)$. After being administered with Fer-1, the level of myocardial infarction area in DIR+Fer-1 group was lower than that in DIR group $(p<0.05)$.

As shown in Figure 1E-G, compared with NS group, the level of CK-MB, ACSL4, ATF4, and CHOP was increased in DS group $(p<0.05)$, I/R group $(p<0.05)$, and DIR group $(p<0.05)$. The level of CK-MB, ACSL4, ATF4, and CHOP in DIR group was higher than that in DS group and I/R group $(p<0.05)$. Moreover, the expression of GPX4 protein in DS group $(p<0.05), \mathrm{I} / \mathrm{R}$ group $(p<0.05)$, and DIR group 
$(p<0.05)$ was decreased when compared with NS group. The level of GPX4 in DIR group was lower than that in DS group and $\mathrm{I} / \mathrm{R}$ group $(p<0.05)$. After being administered with Fer-1, the level of CK-MB, ACSL4, ATF4, and CHOP in DIR+Fer-1 group was lower than that in DIR group $(p<0.05)$. But GPX4 protein level was increased $(p<0.05)$.

Left ventricular function was assessed by measuring hemodynamic parameters (Table 3). Compared with NS group, HR, LVSP, +dp/dt, and $-\mathrm{dp} / \mathrm{dt}$ were elevated in DS group $(p<0.05)$. At the time of $10 \mathrm{~min}$ before ischemia, the hemodynamic parameters in DIR group were lower than those in the corresponding I/R group $(p<0.05)$. At the time of $2 \mathrm{~h}$ after reperfusion, the hemodynamic parameters in the $I / R$, DIR, and DIR+Fer-1 groups were significantly lower than those in the corresponding baseline $(p<0.05)$, the hemodynamic parameters in the I/R and DIR groups were significantly decreased than that in NS group $(p<0.05)$, and the hemodynamic parameters in DIR group were decreased than that in $\mathrm{I} / \mathrm{R}$ group $(p<0.05)$.

However, compared with DIR group, Fer-1 treatment elevated the levels of HR, LVSP, $+\mathrm{dp} / \mathrm{dt}$, and $-\mathrm{dp} / \mathrm{dt}$ in DIR+Fer-1 group $(p<0.05)$, suggesting that Fer-1 could improve cardiac function during myocardial $\mathrm{I} / \mathrm{R}$ in diabetic rats.

\section{Ferroptosis inhibitor Fer-1 can alleviate myocardial H9c2 cell damage during HG}

It was first demonstrated that promoting ferroptosis by Era could aggravate cell injury in $\mathrm{H} 9 \mathrm{c} 2$ cells. As shown in Figure $2 \mathrm{~A}-\mathrm{H}$, compared with normal group, the cell viability and SOD levels of H9c2 cells in Era group were decreased $(p<0.05)$. LDH, MDA, ROS, and intracellular $\mathrm{Fe}^{2+}$ concentration values were increased $(p<0.05)$. The expression of ACSL4 was increased $(p<0.05)$, and the expressions of GPX4 were decreased $(p<0.05)$.

It was subsequently demonstrated that inhibition of ferroptosis could reduce cell injury in the process of $\mathrm{H} 9 \mathrm{c} 2$ cell damage induced by $\mathrm{HG}$. As shown in Figure $3 \mathrm{~A}-\mathrm{N}$, compared with normal group, cell viability, SOD, GPX4, and BCL-2 levels in HG group were decreased $(p<0.05)$. LDH, MDA, ROS, intracellular $\mathrm{Fe}^{2+}$ concentration, ACSL4, apoptosis rate, and BAX levels were elevated $(p<0.05)$. Compared with HG group, cell viability, SOD, GPX4, and BCL-2 in HG+Fer-1 group were increased $(p<0.05)$. LDH, MDA, ROS, intracellular $\mathrm{Fe}^{2+}$ concentration, ACSL4, apoptosis rate, and BAX levels were decreased $(p<0.05)$.

\section{Ferroptosis inhibitor Fer-1 can alleviate myocardial $\mathrm{H} 9 \mathrm{c} 2$ cell damage during hypoxia reoxygenation}

It was then demonstrated that inhibition of ferroptosis could reduce cell injury in the process of $\mathrm{H} 9 \mathrm{c} 2$ cell damage induced by $\mathrm{H} / \mathrm{R}$. As shown in Figure 4A-N, compared with normal group, cell viability, SOD, GPX4, and BCL-2 levels in $\mathrm{H} / \mathrm{R}$ group were decreased $(p<0.05)$, LDH, MDA, ROS, intracellular $\mathrm{Fe}^{2+}$ concentration, ACSL4, apoptosis rate, and BAX levels were elevated $(p<0.05)$. Compared with H/R group, cell viability, SOD and GPX4 and BCL-2 levels in $\mathrm{H} / \mathrm{R}+\mathrm{Fer}-1$ group were increased $(p<0.05)$. LDH, MDA, ROS, intracellular $\mathrm{Fe}^{2+}$ concentration, ACSL4, apoptosis rate, and BAX levels were decreased $(p<0.05)$.

\section{Ferroptosis inhibitor Fer-1 can alleviate myocardial $\mathrm{H} 9 \mathrm{c} 2$ cell damage during $\mathrm{HH} / \mathrm{R}$}

Based on the above results, it was subsequently demonstrated that inhibition of ferroptosis could reduce cell injury induced by HH/R. As shown in Figure $5 \mathrm{~A}-\mathrm{K}$, compared with normal group, the levels of cell viability, SOD, and GPX4 in HG group, H/R group, and HH/R group were decreased $(p<0.05)$. LDH, MDA, ROS, intracellular $\mathrm{Fe}^{2+}$ concentration, and ACSL4 levels were increased $(p<0.05)$.

However, compared with $\mathrm{HG}$ group and H/R group, cell viability, SOD, and GPX4 levels in HH/R group were decreased $(p<0.05)$. LDH, MDA, ROS, intracellular $\mathrm{Fe}^{2+}$ concentration, and ACSL4 levels were increased $(p<0.05)$.

Table 3. Hemodynamic Parameters at Baseline and After 2 H of Reperfusion

\begin{tabular}{lcccc}
\hline & $H R(b p m)$ & $L V S P(\mathrm{mmHg})$ & $+d p / d t(\mathrm{mmHg} / \mathrm{s})$ & $d p / d t(\mathrm{mmHg} / \mathrm{s})$ \\
\hline NS & $375 \pm 25$ & $130 \pm 11$ & $6053 \pm 487$ & $5018 \pm 500$ \\
DS & $327 \pm 29^{\mathrm{a}}$ & $104 \pm 9^{\mathrm{a}}$ & $4443 \pm 301^{\mathrm{a}}$ & $3660 \pm 510^{\mathrm{a}}$ \\
10 Min before ischemia (baseline) & $368 \pm 21$ & $126 \pm 14$ & $6079 \pm 570$ & $5198 \pm 490$ \\
I/R & $333 \pm 19^{\mathrm{b}}$ & $107 \pm 10^{\mathrm{b}}$ & $4350 \pm 328^{\mathrm{b}}$ & $3675 \pm 469^{\mathrm{b}}$ \\
DIR & $340 \pm 26$ & $115 \pm 11$ & $4396 \pm 287$ & $3761 \pm 401$ \\
DIR+Fer-1 & & & \\
2 H after reperfusion & $265 \pm 25^{\mathrm{a}, \mathrm{c}}$ & $90 \pm 12^{\mathrm{a}, \mathrm{c}}$ & $4540 \pm 342^{\mathrm{a}, \mathrm{c}}$ & $3450 \pm 335^{\mathrm{a}, \mathrm{c}}$ \\
I/R & $174 \pm 18^{\mathrm{a}-\mathrm{c}}$ & $62 \pm 10^{\mathrm{a}-\mathrm{c}}$ & $2707 \pm 452^{\mathrm{a}-\mathrm{c}}$ & $2051 \pm 272^{\mathrm{a}-\mathrm{c}}$ \\
DIR & $210 \pm 17^{\mathrm{c}, \mathrm{d}}$ & $82 \pm 10^{\mathrm{c}, \mathrm{d}}$ & $4026 \pm 338^{\mathrm{c}, \mathrm{d}}$ & $2837 \pm 347^{\mathrm{c}, \mathrm{d}}$ \\
DIR+Fer-1 & & & \\
\hline
\end{tabular}

Results are expressed as mean \pm standard deviation, $n=8$. Normal+sham (NS), diabetes mellitus+sham (DS), ischemia reperfusion (I/R), diabetes mellitus+I/R (DIR), diabetes mellitus+I/R+Fer-1 (DIR+Fer-1).

${ }^{\mathrm{a}} p<0.05$ versus NS group.

${ }^{\mathrm{b}} p<0.05$ versus their corresponding I/R group.

${ }^{c} p<0.05$ versus their corresponding baseline.

${ }^{\mathrm{d}} p<0.05$ versus their corresponding DIR group.

$\mathrm{HR}$, heart rate; LVSP, left ventricular systolic pressure. 

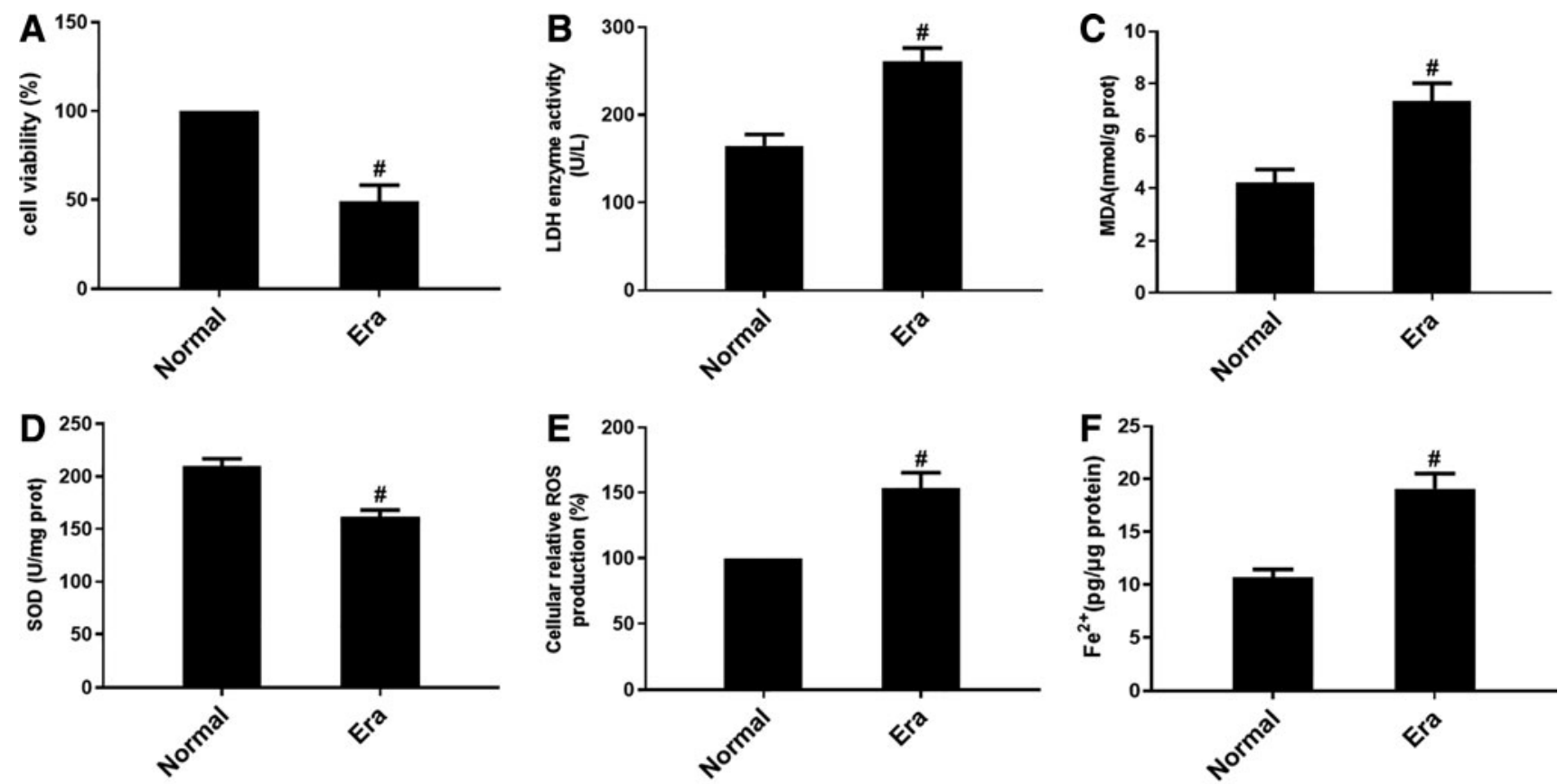

G
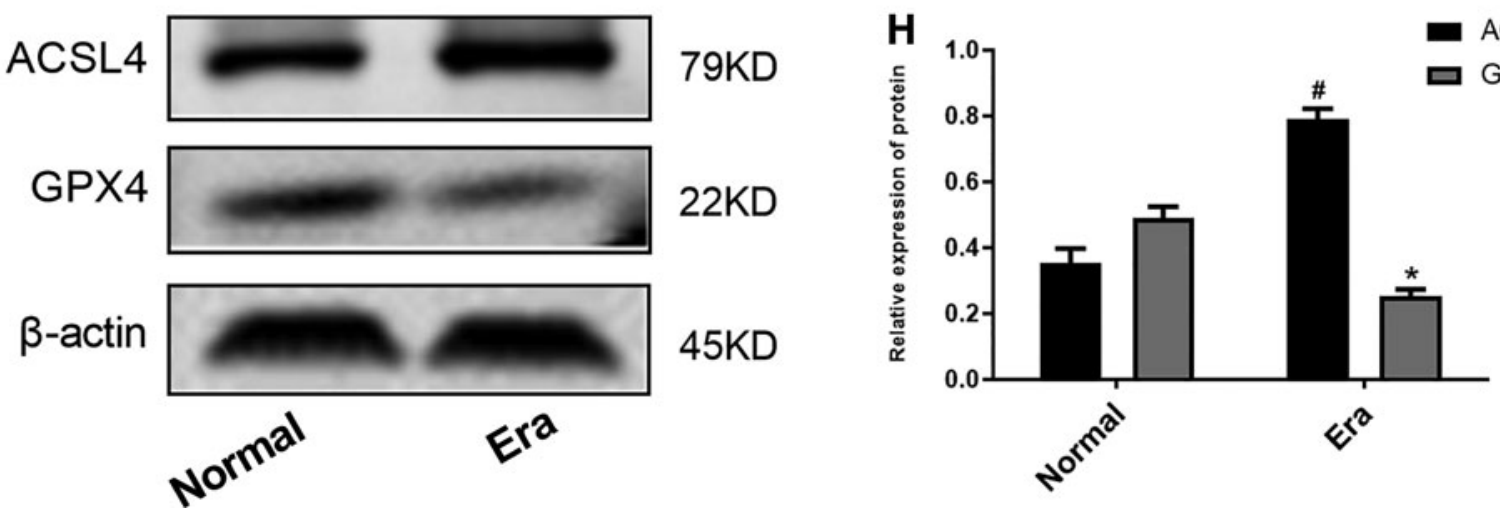

FIG. 2. Promoting ferroptosis by Era could aggravate cell injury. (A) Cell viability was detected by CCK-8. (B-F) LDH, MDA, SOD, cellular ROS production, and $\mathrm{Fe}^{2+}$ concentration levels were detected. (G-H) The protein expression of ACSL4 and GPX4 in H9c2 cell was detected by western blot. ${ }^{\#} p<0.05$, compared with normal group. CCK-8, cell counting kit-8; Era, Erastin; LDH, lactate dehydrogenase; MDA, malondialdehyde; ROS, reactive oxygen species; SOD, superoxide dismutase.

After being administered with Fer-1, cell viability, SOD and GPX4 levels in $\mathrm{HH} / \mathrm{R}+\mathrm{Fer}-1$ group were increased compared with HH/R group $(p<0.05)$. LDH, MDA, ROS, intracellular $\mathrm{Fe}^{2+}$ concentration, and ACSL4 levels were decreased $(p<0.05)$.

\section{Ferroptosis inhibitor can reduce ERS and injury in myocardial $\mathrm{H} 9 \mathrm{c} 2$ cells during $\mathrm{HH} / \mathrm{R}$}

To further validate the role of ERS in ferroptosis-induced cardiomyocyte injury. ERS inhibitor Sa and agonist Tu are used in cell experiments. As shown in Figure 6A-M, compared with $\mathrm{HH} / \mathrm{R}$ group, the levels of cell viability, SOD, and GPX4 in HH/R+Fer-1 group were increased $(p<0.05)$. The levels of $\mathrm{LDH}, \mathrm{MDA}, \mathrm{ROS}$, intracellular $\mathrm{Fe}^{2+}$ concentration, ACSL4, ATF4, and CHOP were decreased $(p<0.05)$. Compared with $\mathrm{HH} / \mathrm{R}+\mathrm{Fer}-1$ group, the levels of cell viability, $\mathrm{SOD}$, and GPX4 in $\mathrm{HH} / \mathrm{R}+\mathrm{Fer}-1+\mathrm{Tu}$ group were decreased $(p<0.05)$. The levels of LDH, MDA, ROS, intracellular $\mathrm{Fe}^{2+}$ concentration, ACSL4, ATF4, and CHOP were increased $(p<0.05)$. Compared with $\mathrm{HH} / \mathrm{R}+\mathrm{Fer}-1+\mathrm{Tu}$ group, the levels of cell viability, SOD, and GPX4 in $\mathrm{HH} / \mathrm{R}+\mathrm{Tu}$ group were decreased $(p<0.05)$. The levels of LDH, MDA, ROS, intracellular $\mathrm{Fe}^{2+}$ concentration, ACSL4, ATF4, and CHOP were increased $(p<0.05)$.

\section{Ferroptosis agonist can aggravate ERS and injury} in myocardial H9c2 cells during $\mathrm{HH} / \mathrm{R}$

As shown in Figure 7A-M, compared with HH/R group, the levels of cell viability, SOD, and GPX4 in $\mathrm{HH} / \mathrm{R}+\mathrm{Era}$ group were decreased $(p<0.05)$. The levels of LDH, MDA, ROS, intracellular $\mathrm{Fe}^{2+}$ concentration, ACSL4, ATF4, and $\mathrm{CHOP}$ were increased $(p<0.05)$. Compared with $\mathrm{HH} / \mathrm{R}+\mathrm{Era}$ group, the levels of cell viability, SOD, and GPX4 in $\mathrm{HH} / \mathrm{R}+\mathrm{Era}+\mathrm{Sa}$ group were increased $(p<0.05)$. The levels of LDH, MDA, ROS, intracellular $\mathrm{Fe}^{2+}$ concentration, ACSL4, ATF4, and CHOP were decreased $(p<0.05)$. Compared with 

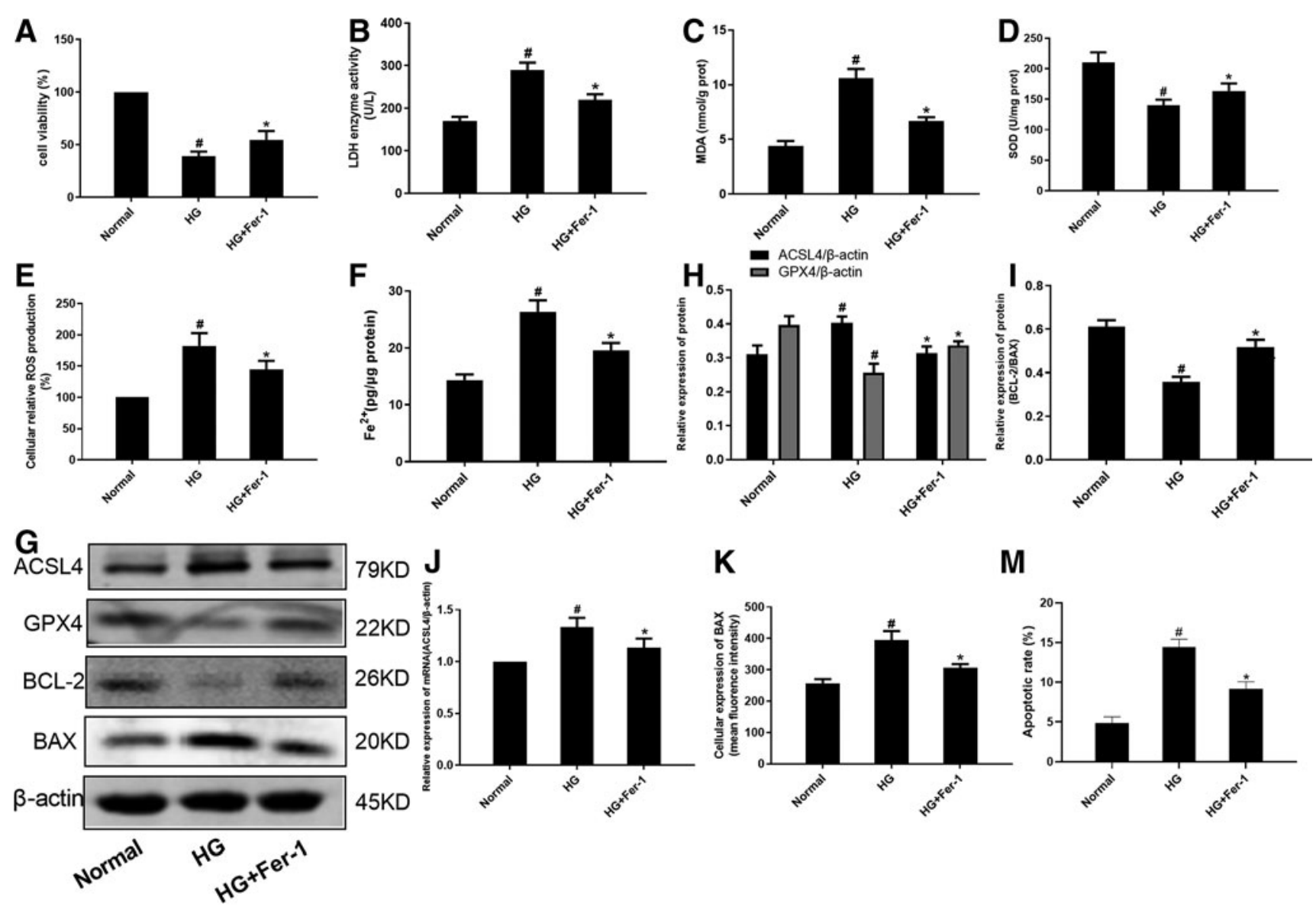

K

M
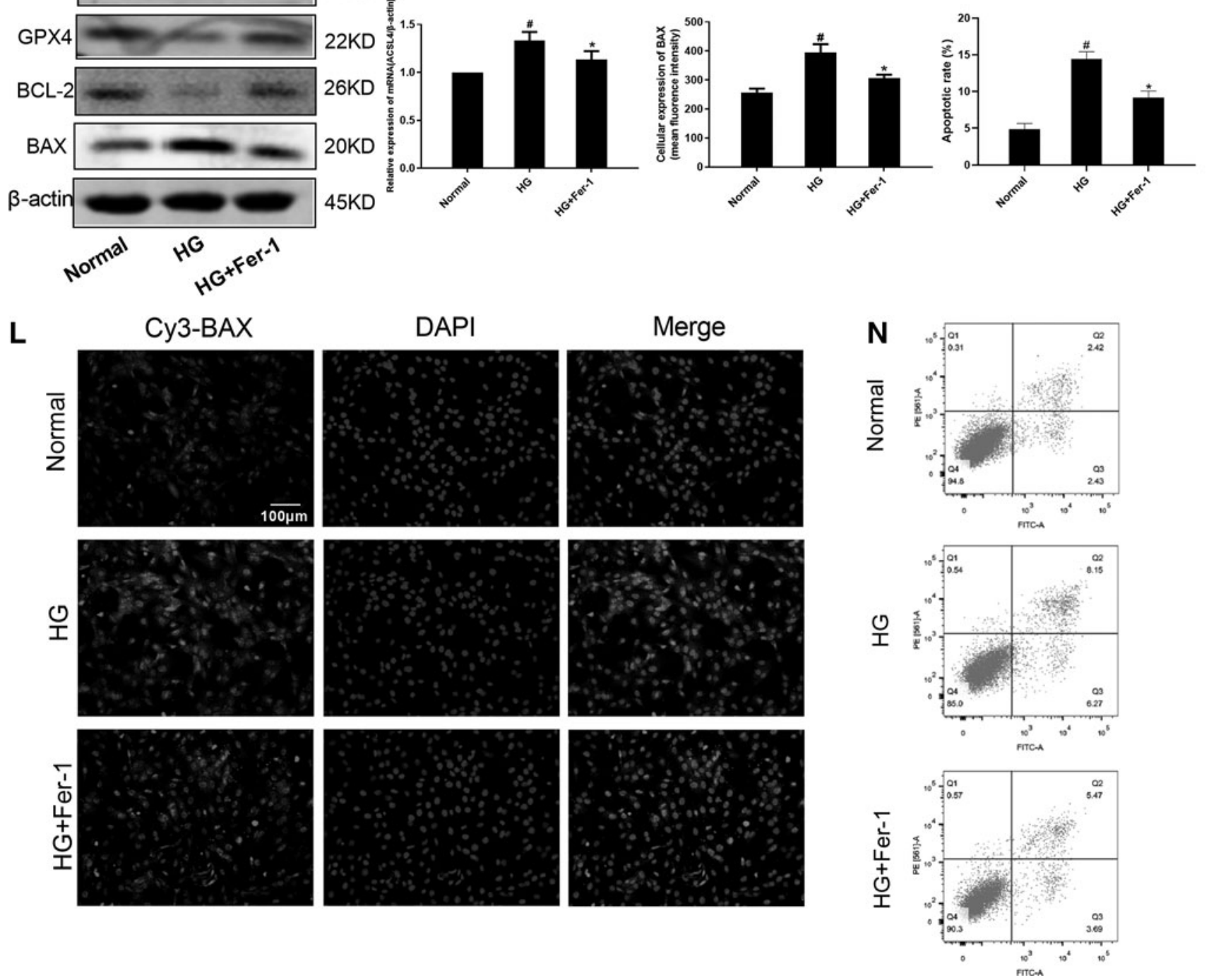

FIG. 3. Inhibition of ferroptosis could reduce cell injury in the process of H9c2 cell damage induced by HG. (A) Cell viability was detected by CCK-8. (B-F) LDH, MDA, SOD, cellular ROS production, and $\mathrm{Fe}^{2+}$ concentration levels were detected. (G-I) The protein expression of ACSL4, GPX4, BAX, and BCL-2 in H9c2 cell was detected by western blot. (J) The mRNA level of ACSL4 in H9c2 cell was detected by qRT-PCR. (K, L) The expression of BAX was detected by immunofluorescence. (M, N) The apoptosis rate of H9c2 cells was determined by flow cytometry. ${ }^{\#} p<0.05$, compared with normal group. ${ }^{*} p<0.05$, compared with HG group. HG, high glucose. 

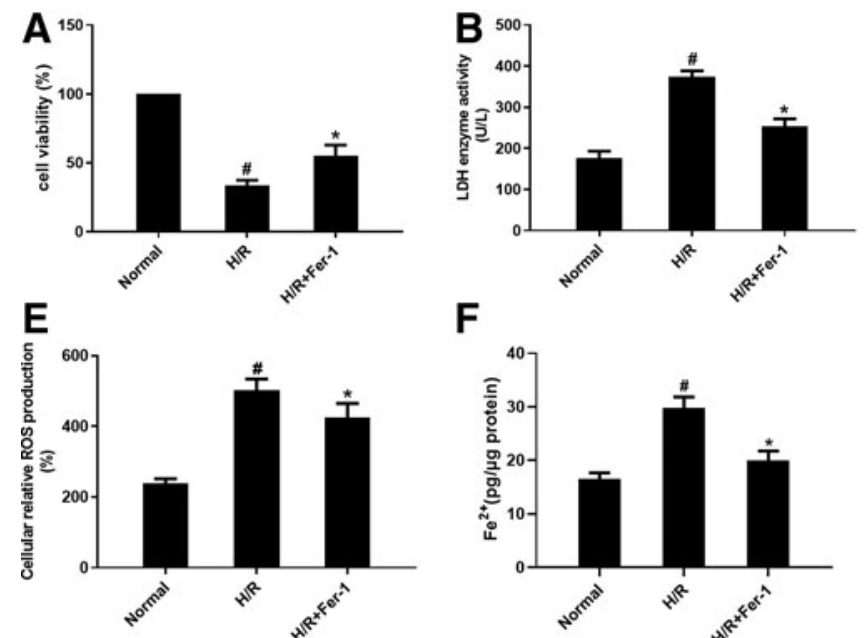

$\mathbf{F}$

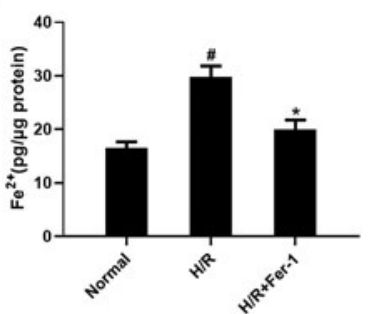

G
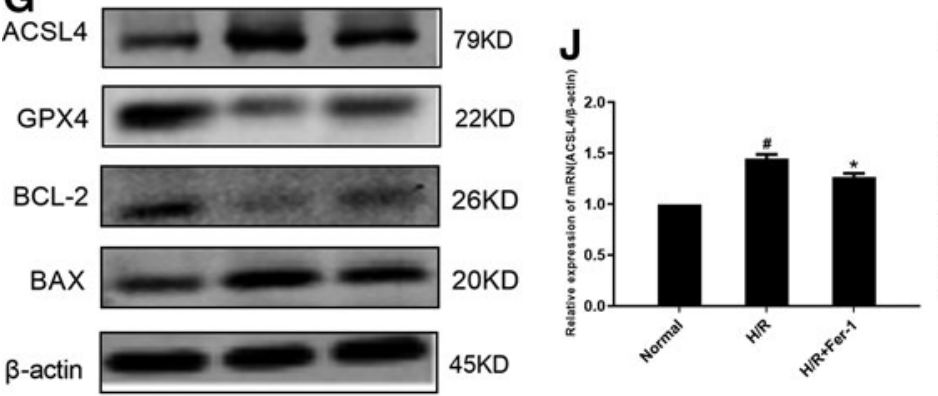

K
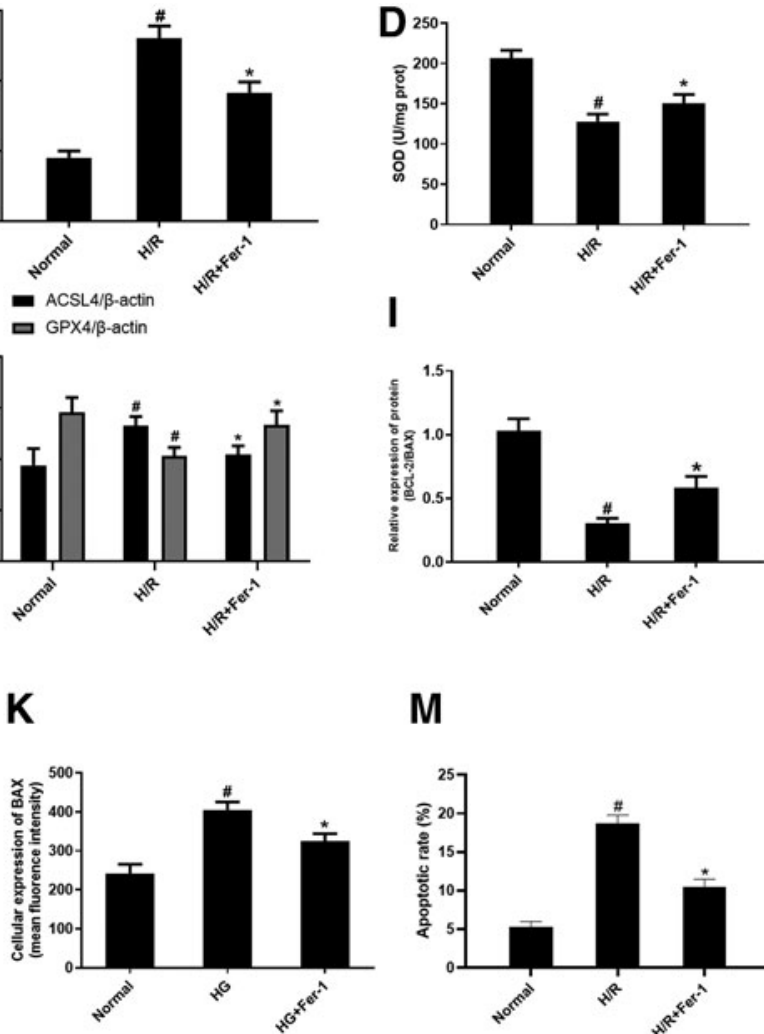

H $=$ ACSL4/B-actin
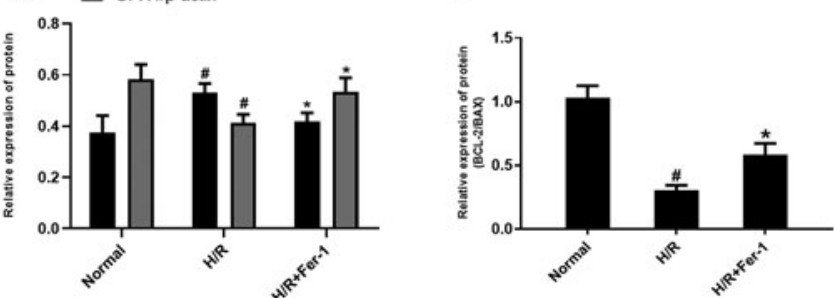

\section{M}

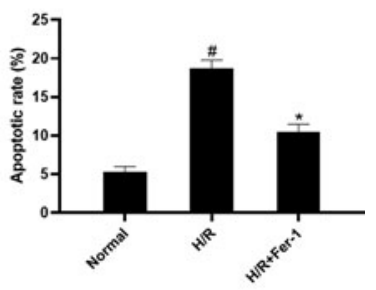

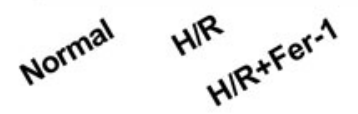

$\mathbf{L}$
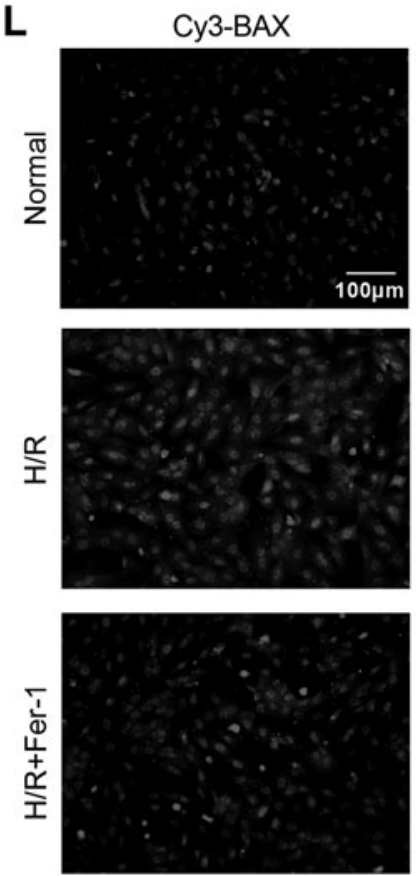
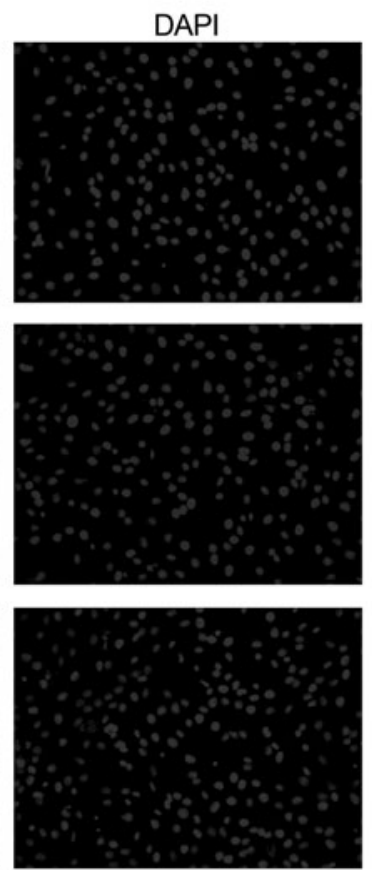
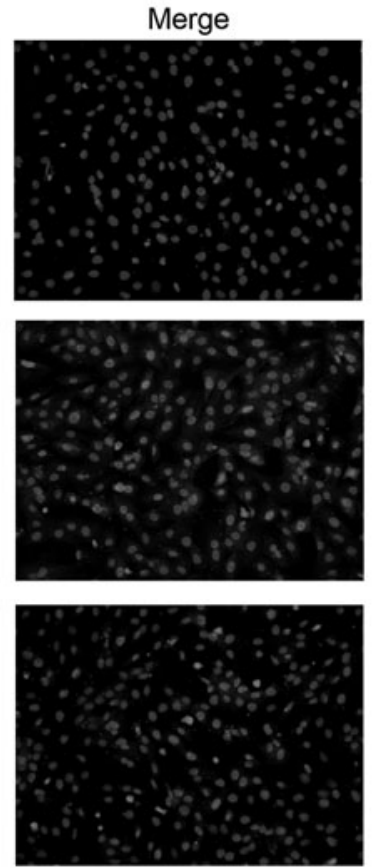
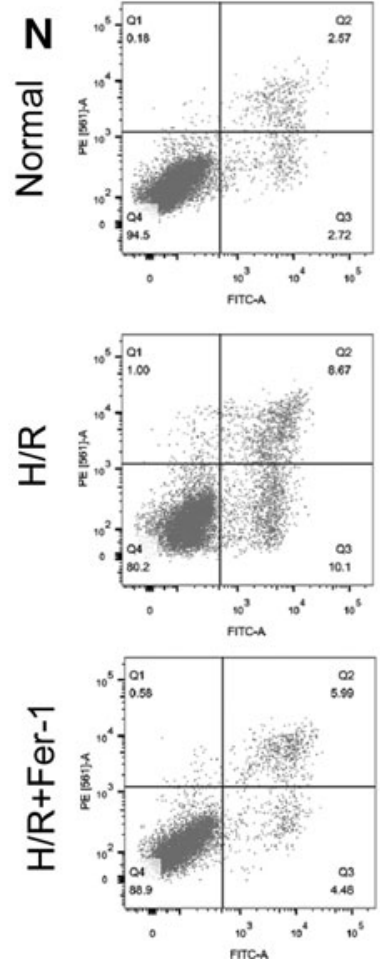

FIG. 4. Ferroptosis inhibitor Fer-1 can alleviate myocardial H9c2 cell damage during H/R. (A) Cell viability was detected by CCK-8. (B-F) LDH, MDA, SOD, cellular ROS production, and $\mathrm{Fe}^{2+}$ concentration levels were detected. (G-I) The protein expression of ACSL4, GPX4, BAX, and BCL-2 in H9c2 cell was detected by western blot. ( $\mathbf{J})$ The mRNA of ACSL4 in H9c2 cell was detected by qRT-PCR. (K, L) The expression of BAX was detected by immunofluorescence. (M, N) The apoptosis rate of $\mathrm{H} 9 \mathrm{c} 2$ cells was determined by flow cytometry. ${ }^{\#} p<0.05$, compared with normal group. ${ }^{*} p<0.05$, compared with $\mathrm{H} / \mathrm{R}$ group. $\mathrm{H} / \mathrm{R}$, hypoxia reoxygenation. 

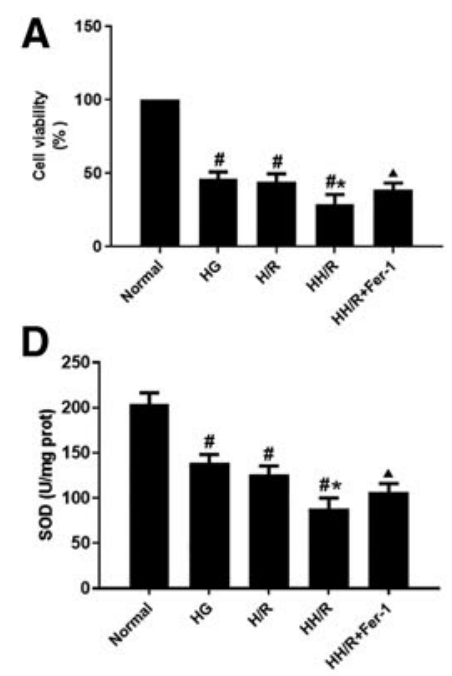

G

ACSL4

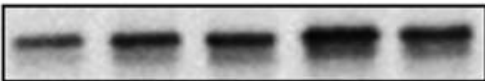

$79 \mathrm{KD}$

GPX4

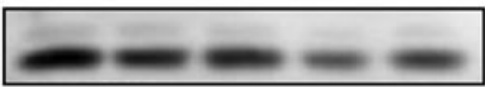

$22 \mathrm{KD}$

$\beta$-actin

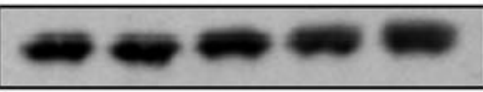

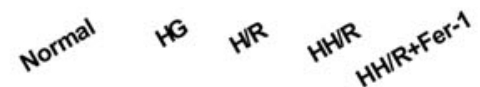

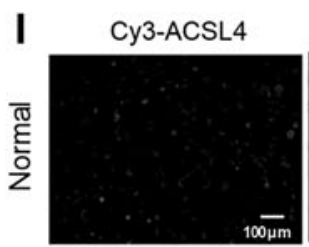

DAPI
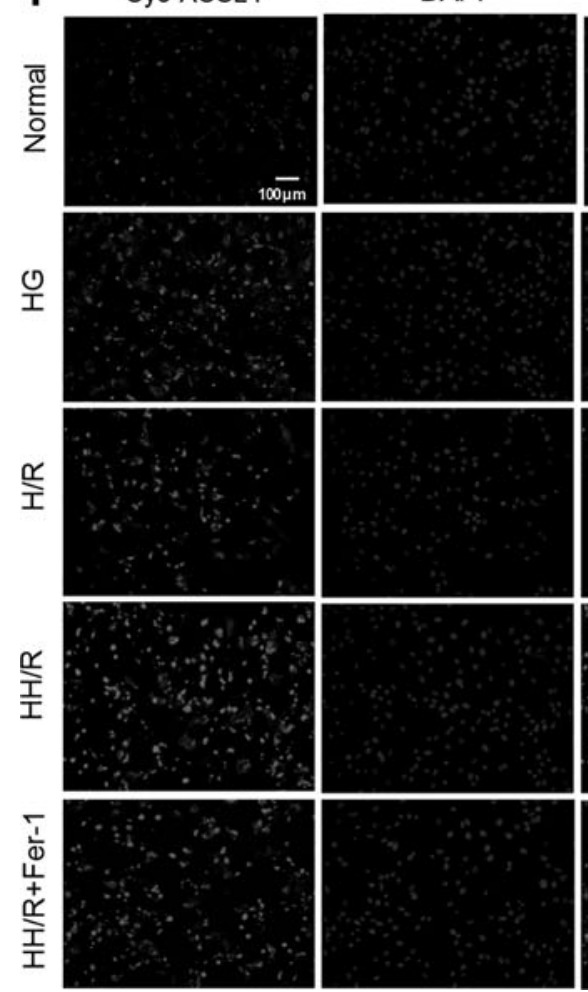

$45 \mathrm{KD}$
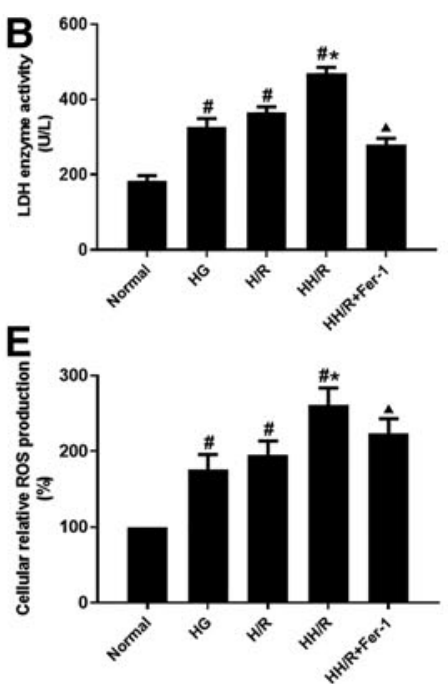

$\mathbf{F}$
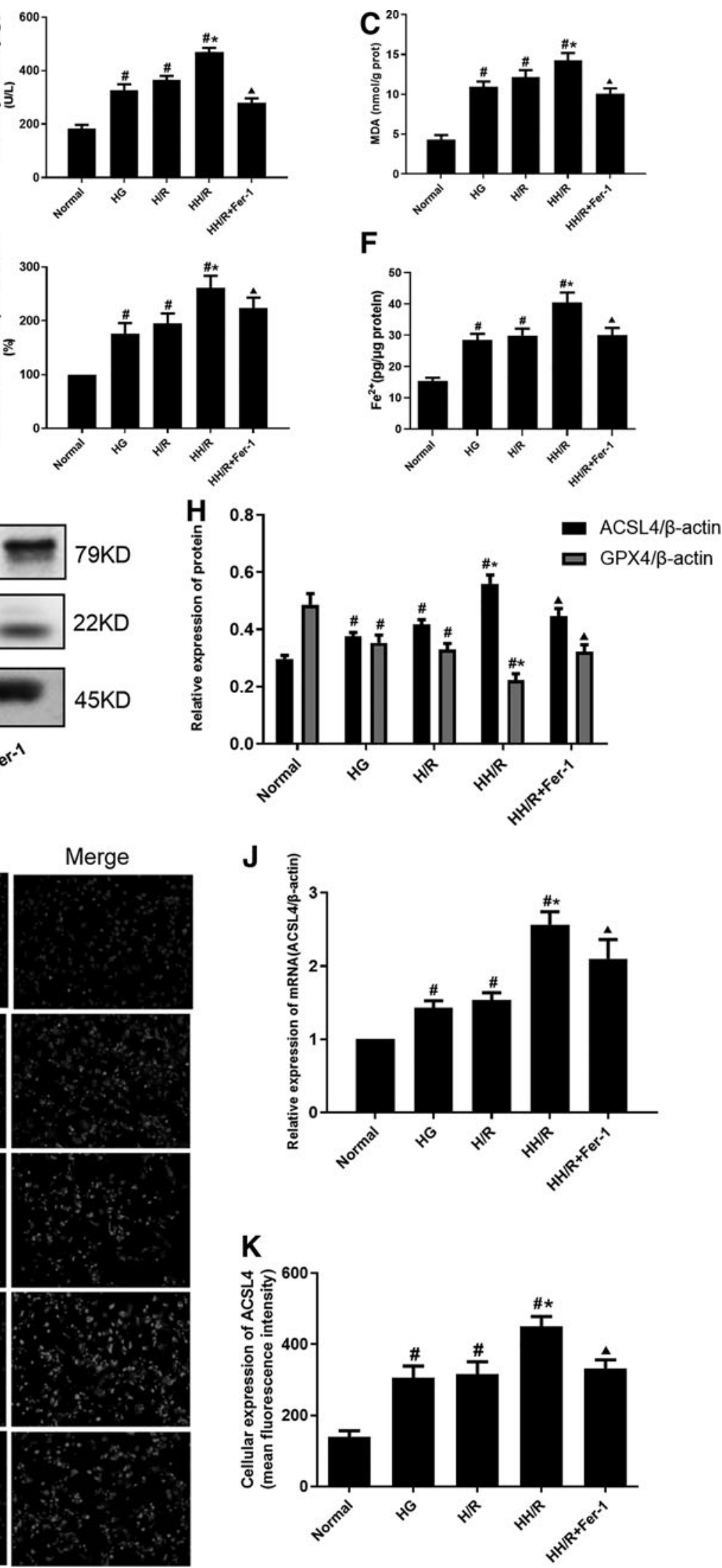

FIG. 5. Ferroptosis inhibitor Fer-1 can alleviate myocardial H9c2 cell damage during HH/R. (A) Cell viability was detected by CCK-8. (B-F) LDH, MDA, SOD, cellular ROS production, and $\mathrm{Fe}^{2+}$ concentration levels were detected. (G, H) The protein expression of ACSL4 and GPX4 in H9c2 cell was detected by western blot. (I, J) The expression of ACSL4 was detected by immunofluorescence. (K) The mRNA level of ACSL4 in H9c2 cell was detected by qRT-PCR. ${ }^{\#} p<0.05$, compared with normal group. ${ }^{*} p<0.05$, compared with HG group and H/R group. ${ }^{*} p<0.05$, compared with HH/R group. $\mathrm{HH} / \mathrm{R}$, high-glucose hypoxia reoxygenation. 
FIG. 6. Ferroptosis inhibitor can reduce the degree of ERS and myocardial injury in $\mathrm{H} 9 \mathrm{c} 2$ cell during $\mathrm{HH} / \mathrm{R}$. (A) Cell viability was detected by CCK-8. (B-F) LDH, MDA, SOD, cellular ROS production, and $\mathrm{Fe}^{2+}$ concentration levels were detected. (G-J) The protein expression of ACSL4, GPX4, ATF4, and CHOP in $\mathrm{H} 9 \mathrm{c} 2$ cell was detected by western blot. (K) The mRNA level of ACSL4, ATF4, and $\mathrm{CHOP}$ in $\mathrm{H} 9 \mathrm{c} 2$ cells was detected by RT-PCR. (L, M) The expression of ACSL4 was detected by immunofluorescence. ${ }^{\#} p<0.05$, compared with $\mathrm{HH} / \mathrm{R}$ group. $* p<0.05$, compared with $\mathrm{HH} / \mathrm{R}+\mathrm{Fer}-1$ group.

$\Delta_{p}<0.05$, compared with HH/R+Fer-1+Tu. Tu, Tunicamycin group.
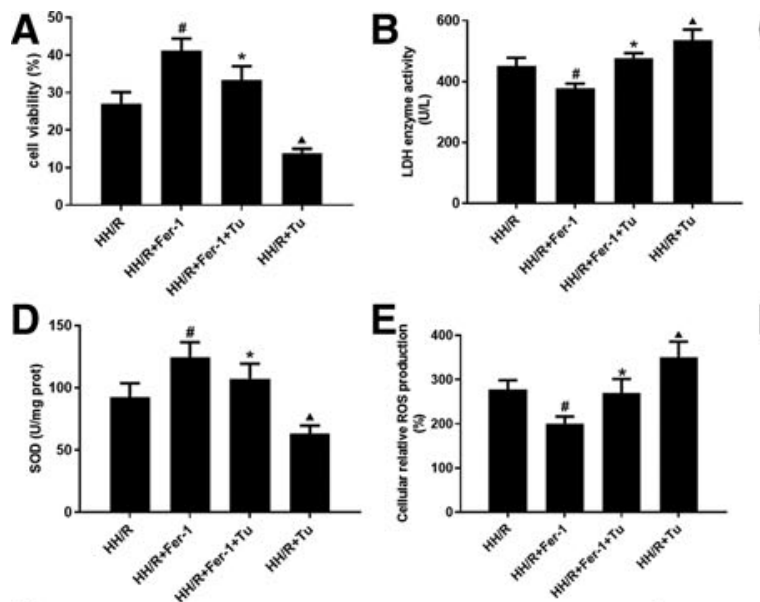

F

G

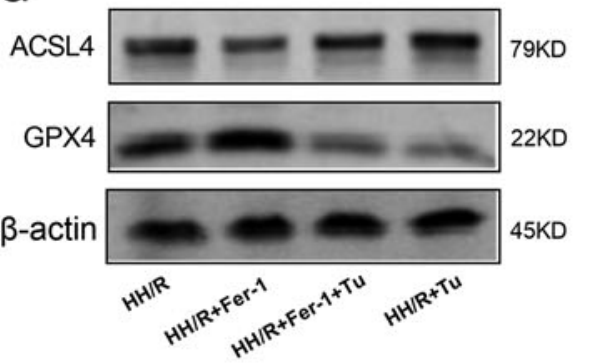

I

H

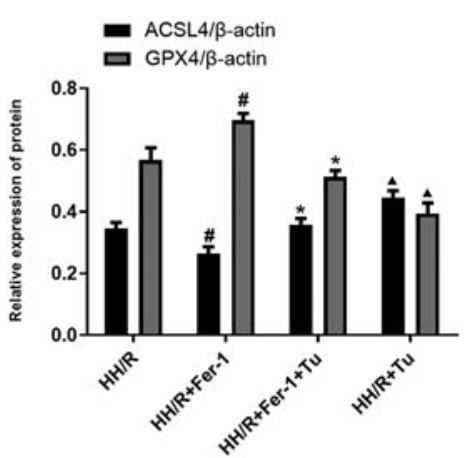

$\mathbf{L}$
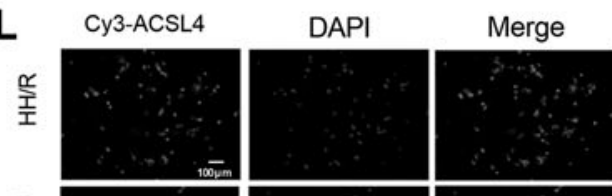

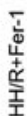
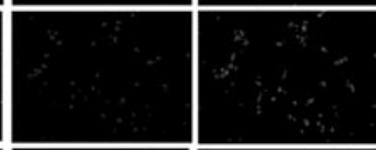

ATF4

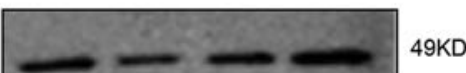

CHOP

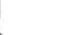

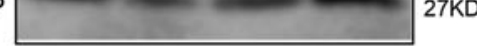

$\beta$-actin
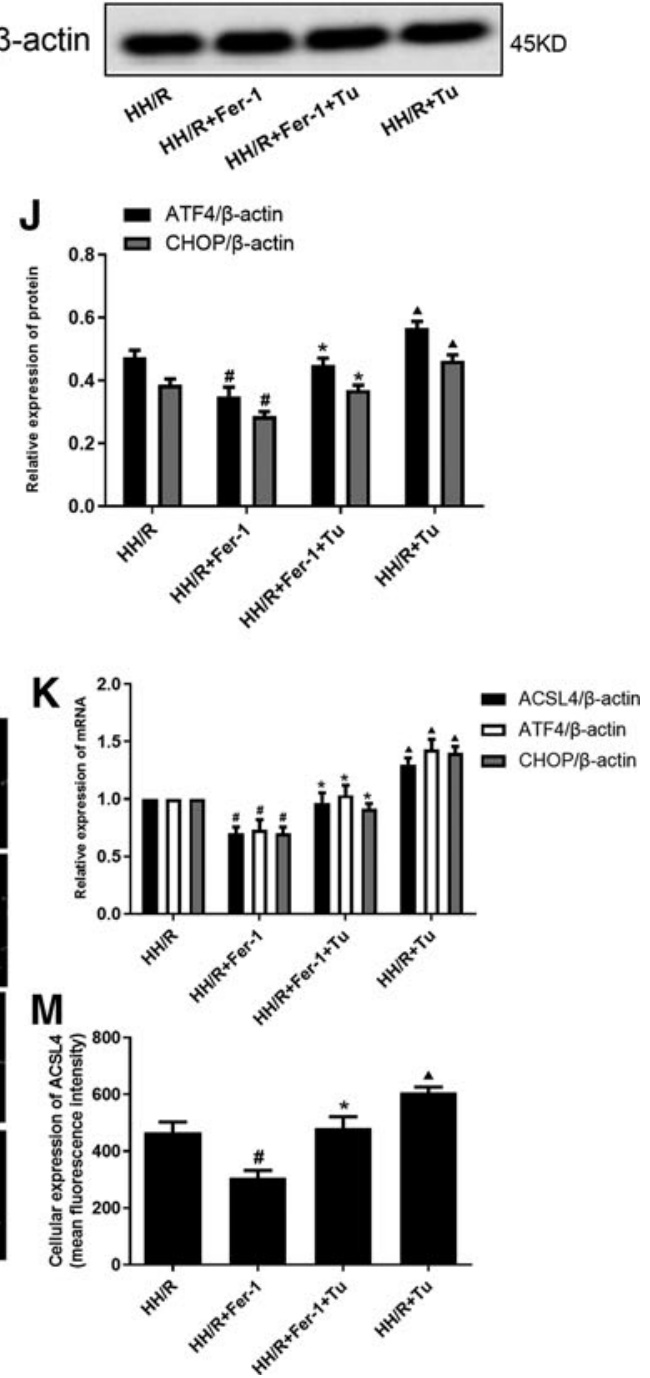

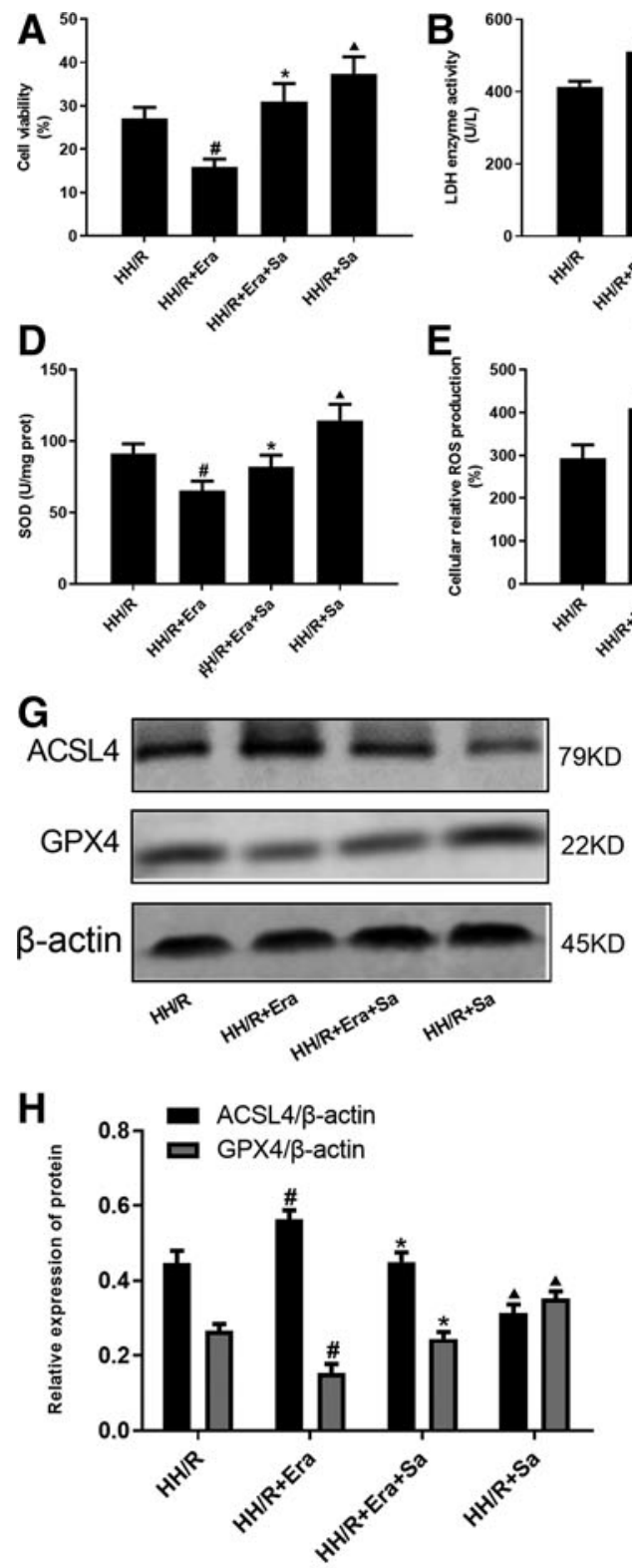

$\mathbf{L}$

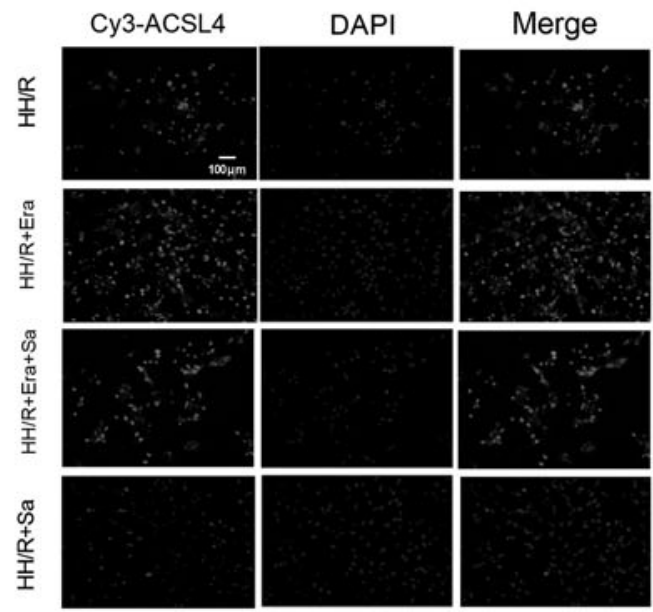

E
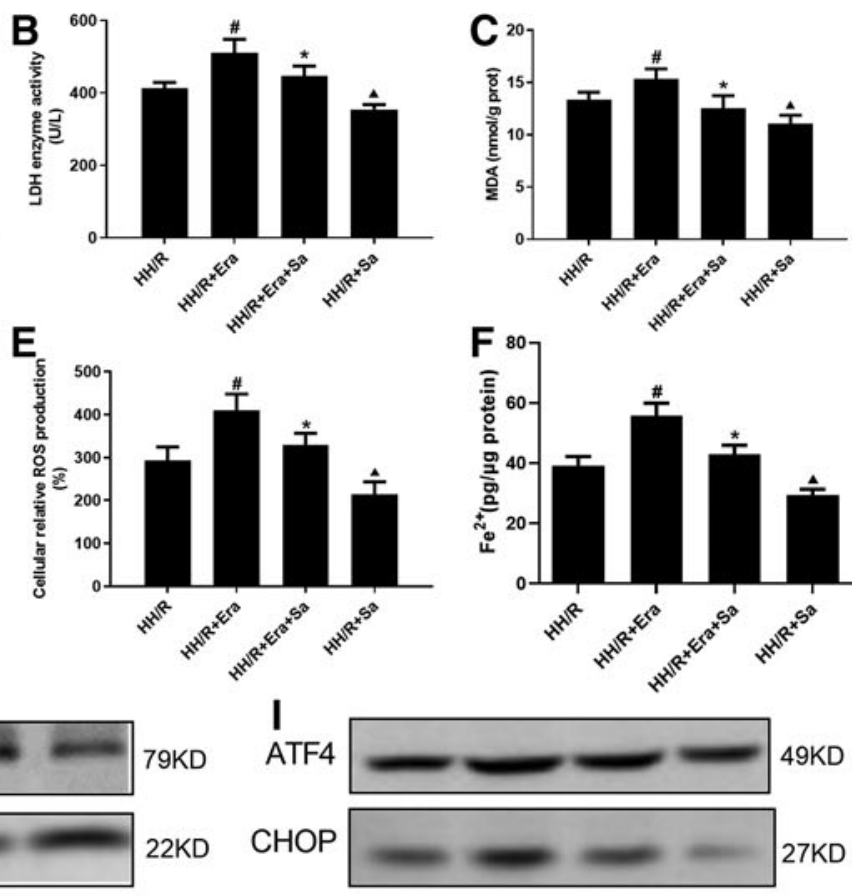

$\beta$-actin
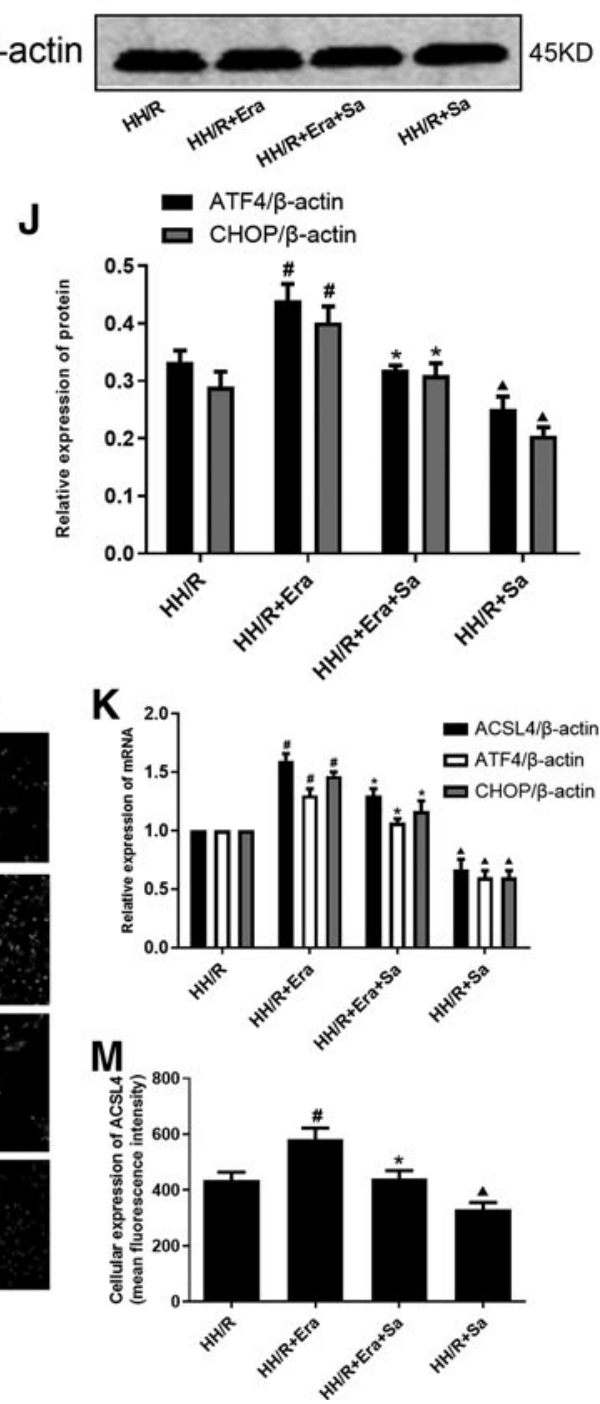

FIG. 7. Ferroptosis agonist can aggravate the degree of ERS and myocardial injury in $\mathrm{H} 9 \mathrm{c} 2$ cell during $\mathrm{HH} / \mathrm{R}$. (A) Cell viability was detected by CCK-8. (B-F) LDH, MDA, SOD, cellular ROS production, and $\mathrm{Fe}^{2+}$ concentration levels were detected. (G-J) The protein expression of ACSL4, GPX4, ATF4, and CHOP in $\mathrm{H} 9 \mathrm{c} 2$ cells was detected by western blot. (K) The mRNA of ACSL4, ATF4, and CHOP in $\mathrm{H} 9 \mathrm{c} 2$ cell was detected by RT-PCR. (L, M) The expression of ACSL4 was detected by immunofluorescence. ${ }^{\#} p<0.05$, compared with $\mathrm{HH} / \mathrm{R}$ group. ${ }^{*} p<0.05$, compared with $\mathrm{HH} / \mathrm{R}+\mathrm{Era}$ group. ${ }^{\mathbf{\Lambda}} p<0.05$, compared with $\mathrm{HH} / \mathrm{R}+\mathrm{Era}+\mathrm{Sa}$. Sa, Salubrinal. 
$\mathrm{HH} / \mathrm{R}+\mathrm{Era}+\mathrm{Sa}$ group, the levels of cell viability, SOD, and GPX4 in $\mathrm{HH} / \mathrm{R}+\mathrm{Sa}$ group were increased $(p<0.05)$. The levels of $\mathrm{LDH}, \mathrm{MDA}, \mathrm{ROS}$, intracellular $\mathrm{Fe}^{2+}$ concentration, ATF4, CHOP, and ACSL4 were decreased $(p<0.05)$.

\section{Discussion}

Epidemiological investigations show that ischemic heart disease is the main cardiovascular complication and cause of death for diabetic patients (Donahoe et al., 2007). Compared with nondiabetic patients, diabetic patients with severe acute myocardial occlusion have more severe disease, more rapid progression, higher mortality, higher perioperative complications, and poorer prognosis (Ngaage et al., 2009; Cavallero et al., 2010; Keller et al., 2010). A large number of studies have shown that diabetic myocardial IRI is closely related to ERS and ROS (Runkel et al., 2013). More importantly, ERS and ROS production are mutually causal.

In diabetic state, the increased ROS is one of the pathological features of diabetic cardiomyopathy (Newsholme et al., 2016). As the pathophysiological characteristics of diabetic patients, increased ROS production and oxidative stress could significantly reduce myocardial tolerance to IRI (Liu et al., 2016b; Zhao et al., 2017). Hyperglycemia caused by diabetes can produce ROS through advanced glycation end products, polyol pathway, and de novo synthesis of triose metabolism (Shen, 2010). ROS can directly lead to oxidative damage of tissues and organs (Polimeno et al., 2013). The damaged cell activates the UPR. Then, the UPR causes ERS due to the changes of redox status, calcium levels, and the decreased function of chaperone protein (Tabas and Ron, 2011).

ERS destroys $\mathrm{Ca}^{2+}$ homeostasis in endoplasmic reticulum, further causing mitochondrial calcium overload and increasing ROS production (De Stefani et al., 2012). The accumulation of ROS activates the downstream caspase family proteins through cascade amplification, which initiates the cell injury process (Wang et al., 2013). Moreover, the key ERS molecules (ATF4 and CHOP) are upregulated, and $\mathrm{CHOP}$ can further induce the expression of proapoptotic proteins during ERS (Zheng et al., 2017; Lee et al., 2018). Therefore, control of the damage of myocardial myocytes caused by ERS and ROS is crucial for the treatment of myocardial IRI.

As a new type of cell death discovered in recent years, ferroptosis is mostly characterized by overloaded irondependent lipid peroxidation and ROS (Dixon et al., 2012). Ferroptosis is regulated by iron metabolism (Manz et al., 2016), system Xc-/GPX4 (Yang et al., 2014), and lipid metabolism (Kagan et al., 2017) pathways. It will further increase the ferroptosis of the marker protein ACSL4. Research studies have shown that antioxidant vitamin E can inhibit ferroptosis (Yang et al., 2016; Kagan et al., 2017). Ferroptosis has been proved to be involved in the development of various diseases, especially cardiovascular diseases (Bai et al., 2018; Kobayashi et al., 2018).

In recent years, it has been found that inhibition of ferroptosis can significantly reduce liver, kidney, brain, and heart defects in mouse models (Gao et al., 2015; Ponikowski et al., 2016). The ferroptosis agonist can significantly reduce the expression of GPX4 in cardiomyocytes, causing dysregulation of iron metabolism and lipid peroxidation in cardiomyocytes, leading to heart failure in rats (Ponikowski et al., 2016). Therefore, the regulation of ferroptosis can affect the level of oxidative stress in cardiomyocytes. Therefore, we hypothesized that myocardial IRI regulated by ferroptosis can change the oxidative stress level of cardiomyocytes, causing the myocardial cell damage through the interaction of ROS with ERS.

In this study, to simulate the effects of I/R on myocardial cells in diabetic patients, rat DS, I/R, and DIR models were, respectively, established. For the in vivo results, the degree of myocardial tissue injury for DIR group was more serious than DS and I/R group. Therefore, it could be demonstrated that diabetes was a risk factor for myocardial IRI. The experiments subsequently proved that after being administered with ferroptosis inhibitor Fer-1, the degree of ERS and injury in DIR rats were decreased. However, Fer-1 was intraperitoneally injected one time before building I/R model. It only verified the effect of Fer-1 on I/R during DS. But whether the effect of inhibiting ferroptosis on both I/R and diabetes was still unknown. And whether ERS involved in this process was also unknown. Therefore, the mechanism was verified in $\mathrm{H} 9 \mathrm{c} 2$ cells in detail.

For the in vitro experiments, it was demonstrated that promoting ferroptosis by Era could directly decrease the cell viability, SOD and GPX4 level, increase LDH, MDA, ROS, intracellular $\mathrm{Fe}^{2+}$, and ACSL4 levels. To further validate the effects of ferroptosis on cardiomyocytes during HH/R, H9c2 cells were stimulated with $\mathrm{HG}$ and $\mathrm{H} / \mathrm{R}$, respectively; then treated with Fer-1. It was found that inhibition of ferroptosis could reduce cell injury in the process of $\mathrm{H} 9 \mathrm{c} 2$ cell damage induced by $\mathrm{HG}$ or $\mathrm{H} / \mathrm{R}$. The mechanism of $\mathrm{HG}-$ and $\mathrm{H} / \mathrm{R}-$ induced injury in H9c2 cells associated with ROS (Qiu et al., 2019). Moreover, hyperglycemia stimulates ROS production and induces oxidative stress (Xu et al., 2014), which is greater in the presence of DM after reperfusion injury, and contributes to the exacerbation of myocardial IRI (Liu et al., 2005).

The decreased SOD can lead to lipid peroxidation and ferroptosis. This involves a complex oxidation feedback regulation mechanism. As an important antioxidant mechanism in the body, SOD can remove ROS in cells and maintain the balance of ROS (Gemma et al., 2007). In the process of ferroptosis, the level of ROS is increased, so the SOD in the cells will be consumed and its level will be reduced. When the production of ROS is prolonged, the endogenous reserves of antioxidants become insufficient, leading to cell damage (Gemma et al., 2007; Peng et al., 2014). Therefore, the decrease of SOD level was accompanied by the occurrence of ferroptosis in this experiment.

Moreover, factors that induce ferroptosis can induce apoptosis. The research studies show that ferroptosis is accompanied by the occurrence of apoptosis in tumor necrosis factor alpha (TNF- $\alpha$ )/D-galactosamine-induced hepatocyte damage (Wang et al., 2019b, 2019c), radiation-induced lung injury (Kim et al., 2017; Li et al., 2019a), and intestinal I/R injury (Du et al., 2019; Li et al., 2019b). The associated factor that links ferroptosis and apoptosis is most likely ERS (Hong et al., 2017). Therefore, the proapoptotic protein BAX, antiapoptotic protein BCL-2, H9c2 cell apoptosis rate that reflected the degree of apoptosis were detected in this experiment. The BAX protein level and apoptosis rate in $\mathrm{HG}$ or $\mathrm{H} / \mathrm{R}$ group were increased when compared with normal group; whereas the BCL-2 protein level was decreased. 


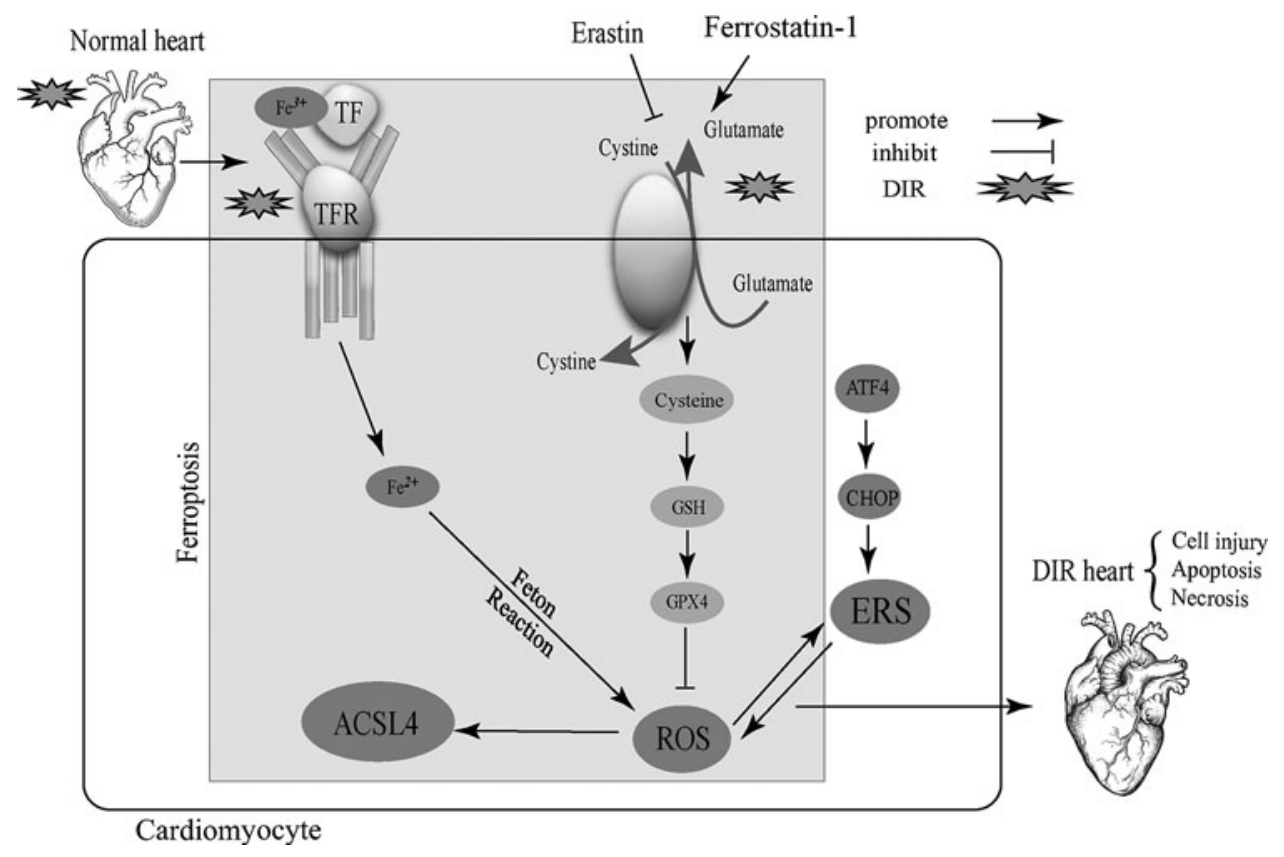

FIG. 8. Ferroptosis participates in the pathological process of diabetes myocardial IRI. The occurrence of ferroptosis is accompanied by the production of ERS. ERS is a cellular response to endoplasmic reticulum dysfunction and can be triggered by ROS. ERS could interact with ROS in the process of ferroptosis, and both of them could cause cardiomyocyte injury. DIR, DM+I/R; IRI, $\mathrm{I} / \mathrm{R}$ injury.

After the cells were administered with Fer-1, the BAX protein level and apoptosis rate were decreased when compared with HG or H/R group; whereas the BCL-2 protein level was elevated. Based on the above results, it was subsequently demonstrated that inhibition of ferroptosis could reduce cell injury in the process of $\mathrm{H} 9 \mathrm{c} 2$ cell damage induced by $\mathrm{HH} / \mathrm{R}$. To further validate the role of ERS in ferroptosis-induced cardiomyocyte injury, ERS inhibitor and agonist were used in cell experiments.

Compared with the ERS agonist group alone, the combination of ferroptosis inhibitor and ERS agonist could reduce the occurrence of ERS, oxidative stress damage, and cardiomyocytes injury. Compared with the ERS inhibitor group alone, the combination of ferroptosis agonist and ERS inhibitor could aggravate the occurrence of ERS, oxidative stress damage, and cardiomyocytes injury. The above results suggested that ferroptosis could aggravate diabetes associated with ERS pathway.

\section{Conclusion}

In conclusion, as shown in Figure 8, ferroptosis participates in the pathological process of diabetes myocardial IRI, inhibition of ferroptosis could alleviate diabetes myocardial IRI. It was deserved that the essential of ferroptosis was oxidative stress injury. Our current results suggested that ERS could interact with ROS in the process of ferroptosis. And both of them could cause cardiomyocyte injury. Ferroptosis was involved in diabetes myocardial IRI through ERS pathway. The occurrence of ferroptosis is accompanied by the production of ERS and activation of ATF4-CHOP pathway. ERS is a cellular response to endoplasmic reticulum dysfunction and can be triggered by ROS, which is produced by the interaction between iron ions and NADPH oxidase during ferroptosis.

However, the ERS inhibitor or agonist was not used in vivo. It was only preliminarily verified that ferroptosis could affect ERS and cardiomyocyte injury. Moreover, in our next experiment, the ERS process and key pathogenic targets in DIR animal model would be further studied. In all, this experiment provided the effective means to prevent and reduce the death of cardiomyocytes to improving and restoring the cardiac function of ischemic cardiomyopathy.

\section{Acknowledgments}

The authors thank the Central Laboratory, Renmin Hospital of Wuhan University (Wuhan, Hubei, China) for their support of our study.

\section{Disclosure Statement}

No competing financial interests exist.

\section{Funding Information}

This study was supported by a grant from the National Natural Science Foundation of China (81671891).

\section{References}

Altunkaynak, H.O., and Ozcelikay, A.T. (2016). Cardioprotective effect of postconditioning against ischemia-reperfusion injury is lost in heart of 8-week diabetic rat. Gen Physiol Biophys 35, 63-69.

Baba, Y., Higa, J.K., Shimada, B.K., Horiuchi, K.M., Suhara, T., Kobayashi, M., et al. (2018). Protective effects of the mechanistic target of rapamycin against excess iron and ferroptosis in cardiomyocytes. Am J Physiol Heart Circ Physiol 314, H659-H668.

Bai, Y.T., Chang, R., Wang, H., Xiao, F.J., Ge, R.L., and Wang, L.S. (2018). ENPP2 protects cardiomyocytes from erastininduced ferroptosis. Biochem Biophys Res Commun 499, 44-51.

Benninger, R.K.P., Remedi, M.S., Head, W.S., Ustione, A., Piston, D.W., and Nichols, C.G. (2011). Defects in beta cell $\mathrm{Ca} 2+$ signalling, glucose metabolism and insulin secretion in 
a murine model of K-ATP channel-induced neonatal diabetes mellitus. Diabetologia 54, 1087-1097.

Cao, S.S., and Kaufman, R.J. (2014). Endoplasmic reticulum stress and oxidative stress in cell fate decision and human disease. Antioxid Redox Signal 21, 396-413.

Cavallero, E., Biondi-Zoccai, G., Mazzanti, A., Moretti, C., Sciuto, F., Omede, P., et al. (2010). Repeat adverse events long after percutaneous coronary revascularization in diabetics. Minerva Cardioangiol 58, 23-34.

De Stefani, D., Bononi, A., Romagnoli, A., Messina, A., De Pinto, V., Pinton, P., et al. (2012). VDAC1 selectively transfers apoptotic $\mathrm{Ca} 2+$ signals to mitochondria. Cell Death Differ 19, 267-273.

Dixon, S.J., Lemberg, K.M., Lamprecht, M.R., Skouta, R., Zaitsev, E.M., Gleason, C.E., et al. (2012). Ferroptosis: an iron-dependent form of nonapoptotic cell death. Cell 149, 1060-1072.

Dixon, S.J., Patel, D.N., Welsch, M., Skouta, R., Lee, E.D., Hayano, M., et al. (2014). Pharmacological inhibition of cystine-glutamate exchange induces endoplasmic reticulum stress and ferroptosis. Elife 3, e02523.

Donahoe, S.M., Stewart, G.C., McCabe, C.H., Mohanavelu, S., Murphy, S.A., Cannon, C.P., et al. (2007). Diabetes and mortality following acute coronary syndromes. JAMA 298, $765-775$.

Du, J., Fan, X., Yang, B., Chen, Y., Liu, K.X., and Zhou, J. (2019). Irisin pretreatment ameliorates intestinal ischemia/reperfusion injury in mice through activation of the Nrf2 pathway. Int Immunopharmacol 73, 225-235.

Gao, M., Monian, P., Quadri, N., Ramasamy, R., and Jiang, X. (2015). Glutaminolysis and transferrin regulate ferroptosis. Mol Cell 59, 298-308.

Gemma, C., Vila, J., Bachstetter, A., and Bickford, P.C. (2007) Oxidative stress and the aging brain: from theory to prevention. In Brain Aging: Models, Methods, and Mechanisms. D.R. Riddle, ed. (Boca Raton, FL).

Hong, S.H., Lee, D.H., Lee, Y.S., Jo, M.J., Jeong, Y.A., Kwon, W.T., et al. (2017). Molecular crosstalk between ferroptosis and apoptosis: emerging role of ER stress-induced p53independent PUMA expression. Oncotarget 8, 115164 115178.

Kagan, V.E., Mao, G., Qu, F., Angeli, J.P., Doll, S., Croix, C.S., et al. (2017). Oxidized arachidonic and adrenic PEs navigate cells to ferroptosis. Nat Chem Biol 13, 81-90.

Keller, P.F., Carballo, D., and Roffi, M. (2010). Diabetes and acute coronary syndrome. Minerva Med 101, 81-104.

Khardori, R., and Nguyen, D.D. (2012). Glucose control and cardiovascular outcomes: reorienting approach. Front Endocrinol 3, 110.

Kim, J.Y., An, Y.M., Choi, W.H., Kim, J.M., Cho, S., Yoo, B.R., et al. (2017). Pro-apoptotic Noxa is involved in ablative focal irradiation-induced lung injury. J Cell Mol Med 21, 711-719.

Kobayashi, M., Suhara, T., Baba, Y., Kawasaki, N.K., Higa, J.K., and Matsui, T. (2018). Pathological roles of iron in cardiovascular disease. Curr Drug Targets 19, 1068-1076.

Korkmaz-Icoz, S., Lehner, A., Li, S., Vater, A., Radovits, T., Hegedus, P., et al. (2015). Mild type 2 diabetes mellitus reduces the susceptibility of the heart to ischemia/reperfusion injury: identification of underlying gene expression changes. J Diabetes Res 2015, 396414.

Kurmus, O., Aslan, T., Ekici, B., Baglan Uzunget, S., Karaarslan, S., Tanindi, A., et al. (2018). Impact of admission blood glucose on coronary collateral flow in patients with ST- elevation myocardial infarction. Cardiol Res Pract 2018, 4059542.

Lee, J.H., Kwon, E.J., and Kim, D.H. (2013). Calumenin has a role in the alleviation of ER stress in neonatal rat cardiomyocytes. Biochem Bioph Res Commun 439, 327-332.

Lee, Y.S., Lee, D.H., Choudry, H.A., Bartlett, D.L., and Lee, Y.J. (2018). Ferroptosis-induced endoplasmic reticulum stress: cross-talk between ferroptosis and apoptosis. Mol Cancer Res 16, 1073-1076.

Li, X., Zhuang, X., and Qiao, T. (2019a). Role of ferroptosis in the process of acute radiation-induced lung injury in mice. Biochem Biophys Res Commun 519, 240-245.

Li, Y., Feng, D., Wang, Z., Zhao, Y., Sun, R., Tian, D., et al. (2019b). Ischemia-induced ACSL4 activation contributes to ferroptosis-mediated tissue injury in intestinal ischemia/reperfusion. Cell Death Differ 26, 2284-2299.

Liu, B., Zhao, C.X., Li, H.K., Chen, X.Q., Ding, Y., and Xu, S.D. (2018). Puerarin protects against heart failure induced by pressure overload through mitigation of ferroptosis. Biochem Biophys Res Commun 497, 233-240.

Liu, C.L., Li, X., Hu, G.L., Li, R.J., He, Y.Y., Zhong, W., et al. (2012). Salubrinal protects against tunicamycin and hypoxia induced cardiomyocyte apoptosis via the PERK-eIF2 alpha signaling pathway. J Geriatr Cardiol 9, 258-268.

Liu, C.L., Zhong, W., He, Y.Y., Li, X., Li, S., and He, K.L. (2016a). Genome-wide analysis of tunicamycin-induced endoplasmic reticulum stress response and the protective effect of endoplasmic reticulum inhibitors in neonatal rat cardiomyocytes. Mol Cell Biochem 413, 57-67.

Liu, D.J., Shang, H.P., and Liu, Y. (2016b). Stanniocalcin-1 protects a mouse model from renal ischemia-reperfusion injury by affecting ROS-mediated multiple signaling pathways. Int J Mol Sci 17, pii: E1051.

Liu, X., Wei, J., Peng, D.H., Layne, M.D., and Yet, S.F. (2005). Absence of heme oxygenase-1 exacerbates myocardial ischemia/reperfusion injury in diabetic mice. Diabetes 54, 778784.

Manz, D.H., Blanchette, N.L., Paul, B.T., Torti, F.M., and Torti, S.V. (2016). Iron and cancer: recent insights. Ann N Y Acad Sci 1368, 149-161.

Ndumele, C.E., Matsushita, K., Lazo, M., Bello, N., Blumenthal, R.S., Gerstenblith, G., et al. (2016). Obesity and subtypes of incident cardiovascular disease. J Am Heart Assoc 5. pii: e003921.

Newsholme, P., Cruzat, V.F., Keane, K.N., Carlessi, R., and de Bittencourt, P.I., Jr. (2016). Molecular mechanisms of ROS production and oxidative stress in diabetes. Biochem J 473, 4527-4550.

Ngaage, D.L., Jamali, A.A., Griffin, S., Guvendik, L., Cowen, M.E., and Cale, A.R. (2009). Non-infective morbidity in diabetic patients undergoing coronary and heart valve surgery. Eur J Cardiothorac Surg 35, 255-259.

Peng, C., Wang, X., Chen, J., Jiao, R., Wang, L., Li, Y.M., et al. (2014). Biology of ageing and role of dietary antioxidants. Biomed Res Int 2014, 831841.

Polimeno, L., Rossi, R., Mastrodonato, M., Montagnani, M., Piscitelli, D., Pesetti, B., et al. (2013). Augmenter of liver regeneration, a protective factor against ROS-induced oxidative damage in muscle tissue of mitochondrial myopathy affected patients. Int J Biochem Cell B 45, 2410-2419.

Ponikowski, P., Voors, A.A., Anker, S.D., Bueno, H., Cleland, J.G., Coats, A.J., et al. (2016). 2016 ESC Guidelines for the diagnosis and treatment of acute and chronic heart failure: The Task Force for the diagnosis and treatment of acute and 
chronic heart failure of the European Society of Cardiology (ESC). Developed with the special contribution of the Heart Failure Association (HFA) of the ESC. Eur J Heart Fail 18, 891-975.

Qi, X., Zhang, Y., Guo, H., Hai, Y., Luo, Y., and Yue, T. (2019). Mechanism and intervention measures of iron side effects on the intestine. Crit Rev Food Sci Nutr 1-13.

Qiu, Z., He, Y.H., Ming, H., Lei, S.Q., Leng, Y., and Xia, Z.Y. (2019). Lipopolysaccharide (LPS) aggravates high glucoseand hypoxia/reoxygenation-induced injury through activating ROS-dependent NLRP3 inflammasome-mediated pyroptosis in H9C2 cardiomyocytes. J Diabetes Res 2019, 8151836.

Rahmani, M., Davis, E.M., Crabtree, T.R., Habibi, J.R., Nguyen, T.K., Dent, P., et al. (2007). The kinase inhibitor sorafenib induces cell death through a process involving induction of endoplasmic reticulum stress. Mol Cell Biol 27, 5499-5513.

Runkel, E.D., Liu, S., Baumeister, R., and Schulze, E. (2013). Surveillance-activated defenses block the ROS-induced mitochondrial unfolded protein response. PLoS Genet 9, e1003346.

Shen, G.X. (2010). Oxidative stress and diabetic cardiovascular disorders: roles of mitochondria and NADPH oxidase. Can J Physiol Pharmacol 88, 241-248.

Shimada, K., Skouta, R., Kaplan, A., Yang, W.S., Hayano, M., Dixon, S.J., et al. (2016). Global survey of cell death mechanisms reveals metabolic regulation of ferroptosis. Nat Chem Biol 12, 497-503.

Stockwell, B.R., Friedmann Angeli, J.P., Bayir, H., Bush, A.I., Conrad, M., Dixon, S.J., et al. (2017). Ferroptosis: a regulated cell death nexus linking metabolism, redox biology, and disease. Cell 171, 273-285.

Sui, X.B., Zhang, R.N., Liu, S.P., Duan, T., Zhai, L.J., Zhang, M.M., et al. (2018). RSL3 drives ferroptosis through GPX4 inactivation and ROS production in colorectal cancer. Front Pharmacol 9, 1371.

Sun, X., Ou, Z., Xie, M., Kang, R., Fan, Y., Niu, X., et al. (2015). HSPB1 as a novel regulator of ferroptotic cancer cell death. Oncogene 34, 5617-5625.

Tabas, I., and Ron, D. (2011). Integrating the mechanisms of apoptosis induced by endoplasmic reticulum stress. Nat Cell Biol 13, 184-190.

Wang, C.H., Wu, S.B., Wu, Y.T., and Wei, Y.H. (2013). Oxidative stress response elicited by mitochondrial dysfunction: implication in the pathophysiology of aging. Exp Biol Med 238, 450-460.

Wang, N., Zeng, G.Z., Yin, J.L., and Bian, Z.X. (2019a). Artesunate activates the ATF4-CHOP-CHAC1 pathway and affects ferroptosis in Burkitt's Lymphoma. Biochem Biophys Res Commun 519, 533-539.

Wang, Y., Chen, Q., Shi, C., Jiao, F., and Gong, Z. (2019b). Mechanism of glycyrrhizin on ferroptosis during acute liver failure by inhibiting oxidative stress. Mol Med Rep 20, 40814090.

Wang, Y., Yang, F., Jiao, F.Z., Chen, Q., Zhang, W.B., Wang, L.W., et al. (2019c). Modulations of histone deacetylase 2 offer a protective effect through the mitochondrial apoptosis pathway in acute liver failure. Oxid Med Cell Longev 2019, 8173016.

Wu, Q., Wang, Q.Q., Guo, Z.D., Shang, Y.P., Zhang, L., and Gong, S.K. (2014). Nuclear factor-kappa B as a link between endoplasmic reticulum stress and inflammation during cardiomyocyte hypoxia/reoxygenation. Cell Biol Int 38, 881887.

Xu, J.J., Li, H.B., Irwin, M.G., Xia, Z.Y., Mao, X.W., Lei, S.Q., et al. (2014). Propofol ameliorates hyperglycemia-induced cardiac hypertrophy and dysfunction via heme oxygenase-1/ signal transducer and activator of transcription 3 signaling pathway in rats. Crit Care Med 42, E583-E594.

Yang, L., Zou, X.J., Gao, X., Chen, H., Luo, J.L., Wang, Z.H., et al. (2009). Sodium tanshinone IIA sulfonate attenuates angiotensin II-induced collagen type I expression in cardiac fibroblasts in vitro. Exp Mol Med 41, 508-516.

Yang, W.S., Kim, K.J., Gaschler, M.M., Patel, M., Shchepinov, M.S., and Stockwell, B.R. (2016). Peroxidation of polyunsaturated fatty acids by lipoxygenases drives ferroptosis. Proc Natl Acad Sci U S A 113, E4966-E4975.

Yang, W.S., SriRamaratnam, R., Welsch, M.E., Shimada, K., Skouta, R., Viswanathan, V.S., et al. (2014). Regulation of ferroptotic cancer cell death by GPX4. Cell 156, 317-331.

Zhang, G.G., Cai, H.Q., Li, Y.H., Sui, Y.B., Zhang, J.S., Chang, J.R., et al. (2013). Ghrelin protects heart against ERS-induced injury and apoptosis by activating AMP-activated protein kinase. Peptides 48, 156-165.

Zhang, Z.W., Wu, Y., Yuan, S., Zhang, P., Zhang, J.Y., Li, H.Y., et al. (2018). Glutathione peroxidase 4 participates in secondary brain injury through mediating ferroptosis in a rat model of intracerebral hemorrhage. Brain Res 1701, 112-125.

Zhao, D., Yang, J., and Yang, L. (2017). Insights for oxidative stress and mTOR signaling in myocardial ischemia/reperfusion injury under diabetes. Oxid Med Cell Longev 2017, 6437467.

Zheng, D.W., Lei, Q., Zhu, J.Y., Fan, J.X., Li, C.X., Li, C., et al. (2017). Switching apoptosis to ferroptosis: metalorganic network for high-efficiency anticancer therapy. Nano Lett 17, 284-291.

Zhu, S., Zhang, Q., Sun, X., Zeh, H.J., 3rd, Lotze, M.T., Kang, R., et al. (2017). HSPA5 regulates ferroptotic cell death in cancer cells. Cancer Res 77, 2064-2077.

$$
\begin{array}{r}
\text { Address correspondence to: } \\
\text { Zhongyuan Xia, MD, PhD } \\
\text { Department of Anesthesiology } \\
\text { Renmin Hospital of Wuhan University } \\
238 \text { Jiefang Road } \\
\text { Wuhan } 430060 \\
\text { P.R. China }
\end{array}
$$

E-mail: xiazhongyuan2005@aliyun.com

Received for publication September 14, 2019; received in revised form October 21, 2019; accepted November 3, 2019. 